\title{
APLICAÇÃO E AVANÇOS DA ESPECTROSCOPIA DE LUMINESCÊNCIA EM ANÁLISES FARMACÊUTICAS
}

\author{
Maria D. P. T. Sotomayor \\ Departamento de Química Analítica, Instituto de Química, Universidade Estadual Paulista, 14801-970 Araraquara - SP, Brasil \\ Iara Lúcia T. Dias* e Marcos R. V. Lanza \\ Curso de Farmácia, Universidade São Francisco, 12916-900 Bragança Paulista - SP, Brasil \\ Altair B. Moreira \\ Departamento de Química e Ciências Ambientais, Universidade Estadual Paulista, 15054-000 São José do Rio Preto - SP, \\ Brasil \\ Lauro T. Kubota \\ Departamento de Química Analítica, Instituto de Química, Universidade Estadual de Campinas, 13083-970 Campinas - SP, Brasil
}

Recebido em 20/10/06; aceito em 30/11/07; publicado na web em 4/9/08

\begin{abstract}
APPLICATION AND ADVANCES IN THE LUMINESCENCE SPECTROSCOPY IN PHARMACEUTICAL ANALYSES. This paper provides a review on the latest advances and applications of the luminescence spectroscopy for the development of pharmaceuticals analyses methods, basically based on the photo- and chemiluminescence. The different forms of the drugs determination on pharmaceuticals through the fluorescence and chemiluminescence are discussed. The analyses include the drugs native fluorescence (liquid and solid-phases); the fluorescence from the oxidizing or reducing forms of the drug; the fluorescence from the chemical derivatization and their photochemistry and hydrolysis reactions. The quenching of luminescence and chemiluminescence generation for the pharmaceutical quantification are also shown. Finally, the trends and future perspectives of the luminescence spectroscopy in the field of the pharmaceutical research are discussed.
\end{abstract}

Keywords: luminescence spectroscopy; drugs; cosmetics analysis;

\section{INTRODUÇÃO}

Devido ao progresso contínuo em técnicas e instrumentos, a indústria farmacêutica busca o emprego de metodologias que ofereçam maior sensibilidade, seletividade, robustez, precisão, exatidão e rapidez. Neste sentido, um grande número de equipamentos de cromatografia líquida de alta eficiência (CLAE) com diversos tipos de detecção domina este ramo industrial. Contudo, o advento da sofisticação de instrumentação automatizada de espectrômetros de luminescência poderá resultar em um substancial aumento de aplicações desta técnica instrumental na indústria farmacêutica, principalmente, no que se refere à análise diretamente na matriz do medicamento.

A espectroscopia de luminescência é uma ferramenta analítica extremamente sensível e tem sido amplamente aplicada na resolução de problemas que requerem baixos limites de detecção, podendo ser facilmente encontrados na literatura muitos trabalhos mostrando análises ao nível de traços. ${ }^{1-6} \mathrm{~A}$ sensibilidade inerente a esta técnica é consideravelmente maior em comparação a outras metodologias, entre elas a espectrofotometria UV/visível, apresentando limites de detecção de até três ordens de grandeza menores, os quais normalmente se encontram na faixa de $\mathrm{ng}^{-1}$, sendo conseqüência do baixo sinal de fundo que as medidas fluorescentes apresentam. Diferentemente do que ocorre no fenômeno da luminescência, nas medidas de absorbância o sinal está associado à atenuação da intensidade de um feixe de radiação por uma espécie absorvente. Nos casos onde a quantidade da espécie é pequena, esta atenuação é menor, tornando assim a detecção da espécie difícil. Outra característica importante da luminescência diz respeito à seletividade, porque espécies com rendimentos quânticos de fluorescência apreciáveis são menos co-

*e-mail: iaratescarollo@terra.com.br muns do que substâncias cuja fluorescência não pode ser detectada. Desta forma, moléculas fluorescentes apresentam comprimento de onda característico de excitação e/ou emissão. Adicionalmente, o comprimento de onda de excitação de moléculas fluorescentes está localizado em uma faixa de comprimento de onda diferente do espectro de emissão. ${ }^{7}$

Outra vantagem que apresenta os métodos luminescentes é sua ampla faixa linear de resposta. Além disso, a sensibilidade e seletividade oferecidas pela espectroscopia de luminescência têm encontrado amplo uso na análise de numerosos compostos de interesse farmacêutico, biológico, ambiental e industrial. ${ }^{8-10} \mathrm{~A}$ estas características devem ser adicionadas a simplicidade instrumental e o baixo custo de manutenção e análise, quando comparados com outros métodos analíticos.

Desta forma, medidas da intensidade luminescente têm permitido a determinação quantitativa seletiva e sensível de uma variedade de princípios ativos de uso farmacêutico. Contudo, apesar de todas as vantagens oferecidas pelos métodos luminescentes, somente certas classes de substâncias exibem luminescência nativa, como conseqüência dos processos de desativação que ocorrem em uma molécula, ${ }^{11}$ além disto, devem ser considerados os efeitos de espalhamento e reabsorção. Isto tem limitado o uso dos métodos luminescentes quando comparados a outros métodos analíticos, como cromatografia e espectrometria UV/visível. Apesar disto, é muitas vezes possível converter moléculas não-fluorescentes em derivados fluorescentes usando reagentes específicos, ou aproveitar a fluorescência de compostos que reagem quantitativamente com o analito de interesse, de tal forma que a quantificação indireta do analito é possível. ${ }^{12-17}$

Por outro lado, é possível aproveitar a versatilidade nos modos de amostragem e de softwares com mais recursos, oferecidos pelos atuais instrumentos disponíveis no mercado, com os quais podem ser avaliadas novas técnicas que antes eram difíceis de serem aplicadas, 
tais como a espectroscopia de fluorescência sincronizada de ângulo variável para soluções diluídas; observação da fluorescência frontal de soluções turvas; análise de amostras sólidas, géis, filmes e pulverizadas, e até adaptada para o uso de fibras ópticas ${ }^{18-22}$ para amostras fluorescentes contidas em lâminas de cromatografia de camada delgada ou em placas contendo pequenas cavidades empregadas em testes imuno-enzimáticos. . $^{8,23,24}$

Considerando-se a potencialidade de aplicação da espectroscopia de luminescência na área farmacêutica, este artigo visa descrever os principais avanços alcançados, nos últimos anos, na determinação de fármacos, principalmente em formulações comerciais, no intuito de demonstrar o desenvolvimento e potencial que esta metodologia apresenta.

\section{PRINCÍPIOS BÁSICOS DA ESPECTROSCOPIA DE LUMINESCÊNCIA}

A luminescência envolve vários tipos de fenômenos ópticos; os mais difundidos referem-se à fluorescência molecular, à fosforescência e à quimiluminescência. ${ }^{11}$ Contudo, cabe ressaltar que ainda existem a sonoluminescência, ${ }^{25-28}$ a mecano- ou tribulominescência, ${ }^{29-34}$ a radioluminescência, ${ }^{35-38}$ a termoluminescência, ${ }^{34,39,40}$ a bioluminescência, ${ }^{41}$ entre outros. Nesta revisão, serão abordados trabalhos envolvendo a determinação de fármacos baseados em fenômenos fotoluminescentes e quimiluminescentes.

Os métodos baseados em fluorescência e fosforescência são aqueles nos quais a excitação da molécula é conduzida pela absorção de fótons. Como consequiência, os dois fenômenos são muitas vezes referidos e/ou classificados como métodos fotoluminescentes. Neste caso, a molécula é inicialmente excitada e promovida para um estado eletrônico de maior energia, cujo retorno ao estado fundamental é acompanhado pela emissão de radiação eletromagnética (Figura 1S - material suplementar). Contudo, é importante salientar que a absorção do fóton em fluorescência e fosforescência envolve transições eletrônicas diferentes.

Como observado na Figura 1S, do material suplementar, a energia eletrônica responsável pela transição fluorescente não envolve uma mudança no número quântico do spin do elétron, e passa do nível $\mathrm{S}_{0} \rightarrow \mathrm{S}_{1}$, emitindo radiação desde o nível excitado $\mathrm{S}_{1}$ para algum dos níveis vibracionais do estado eletrônico $S_{0}$. Como conseqüência, a fluorescência possui tempos de vida extremamente curtos, com a luminescência cessando quase que imediatamente, por volta de $10^{-9}$ a $10^{-6} \mathrm{~s}$ (ns a $\mu \mathrm{s}$ ). A fluorescência é emitida em comprimentos de onda maiores àqueles de excitação, deslocando-se entre 50 e 150 $\mathrm{nm}$, quando comparado ao comprimento de onda da luz usado para a excitação da molécula. ${ }^{11,42,43}$

Por outro lado, uma mudança no numero quântico de spin do elétron acompanha as emissões fosforescentes, envolvendo transições proibidas de elétrons provenientes de um estado excitado tripleto (com spin diferente ao original) para um estado fundamental singleto $\left(\mathrm{T}_{1} \rightarrow \mathrm{S}_{0}\right)$. Como conseqüência, a radiação existe por um tempo no qual pode ser facilmente detectável após o término da irradiação, entre $10^{-4}$ e $10 \mathrm{~s}$. Contudo, este tipo de transição é menos provável que a transição envolvendo dois estados singletos (fluorescência), já que processos paralelos de desativação como a conversão interna e externa, e o relaxamento vibracional, podem competir com ela (Figura 1S). Desta forma, a emissão de transições fosforescentes tem sido comumente observada apenas em baixas temperaturas, em meios altamente viscosos ou em moléculas adsorvidas em superfícies sólidas para introduzir rigidez ao sistema.

Apesar das vantagens que possam ser enxergadas neste tipo de fotoluminescência, não se deve esquecer a supressão da fosforescência originada pelo oxigênio molecular, o qual em seu estado fundamental é um tripleto $\left({ }^{3} \Sigma\right)$ possuindo dois estados singletos conhecidos como oxigênio ${ }^{1} \Delta$ e oxigênio ${ }^{1} \Sigma$, cujas energias de excitação são de aproximadamente 23 e $38 \mathrm{kcal} \mathrm{mol}^{-1}$, respectivamente. ${ }^{11}$ Assim, moléculas excitadas, que possuam energia menor ou igual a $23 \mathrm{kcal} \mathrm{mol}^{-1}$, podem ter sua luminescência suprimida através da transferência de energia para o oxigênio tripleto, produzindo o oxigênio singleto $\left({ }^{1} \Delta\right)$. Contudo, apesar deste fenômeno de supressão ser muitas vezes indesejado, diversas técnicas de supressão têm sido usadas como ferramentas para aplicações nas áreas de bioquímica e médica. ${ }^{41,44}$

O terceiro tipo de luminescência, a quimiluminescência (Esquema 1), está baseada na emissão de luz de uma espécie excitada que é gerada no curso de uma reação química, ao contrário dos processos fotoluminescentes acima citados, onde a molécula emite luz após absorção de fótons. Desde que a emissão é gerada sem luz, nenhuma fonte será usada durante a medida do sinal. Desta forma, quando usado um espectrômetro fluorescente convencional (Figura 1) a fonte de luz será desligada durante a etapa de medida, para não interferir com o sinal de interesse.

A quimiluminescência é caracterizada por sua alta sensibilidade, ampla faixa linear de resposta, ausência de efeitos de espalhamento e simplicidade de instrumentação, tendo sido empregada na determinação de vários fármacos importantes e de amplo uso. ${ }^{3,29}$

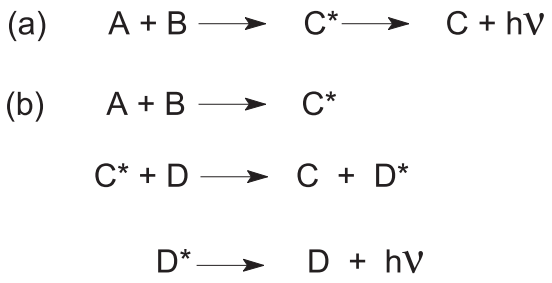

Esquema 1. Representação esquemática da geração de quimiluminescência mostrando a emissão direta (a) onde a molécula excitada $C^{*}$ pode decair para o estado fundamental emitindo luz, e a emissão indireta $(b)$ na qual a espécie excitada $C^{*}$ transfere energia para um aceptor $D$ adequado, a partir do qual se origina a emissão. Na quimiluminescência o processo de emissão de luz ocorre porque uma molécula excitada (aquela que emitirá luz) é formada em uma reação química

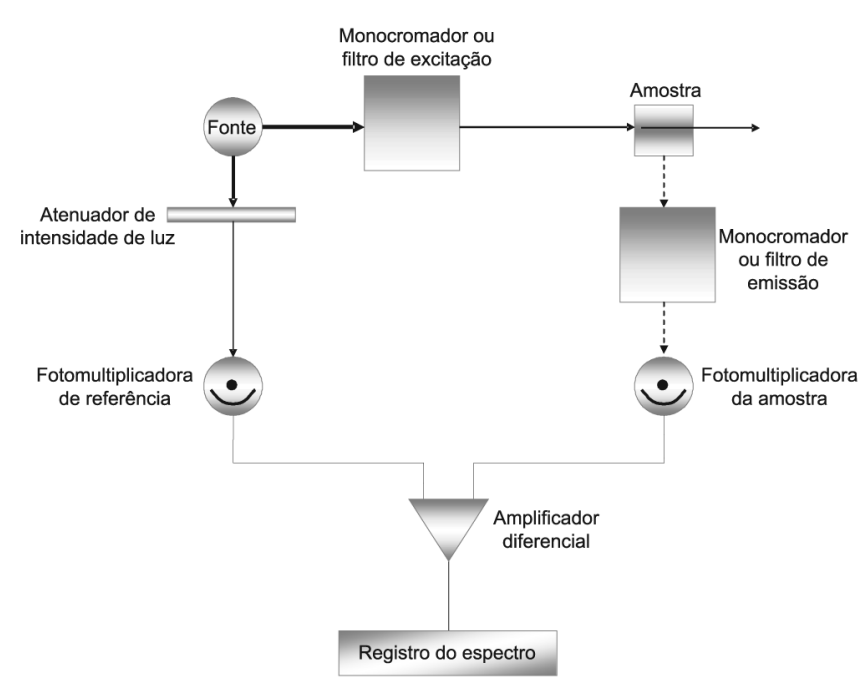

Figura 1. Representação esquemática de um luminômetro típico. A fluorescência proveniente da amostra é propagada em todas as direções, porém é mais convenientemente observada em ângulos retos ao feixe de excitação, empregando arranjo óptico adequado de lentes e espelhos. Para uso em quimiluminescência a fonte é desligada e o sistema comporta-se basicamente como um fotômetro 
Sistemas quimiluminescentes como luminol, ${ }^{44-47}$ métodos quimiluminescentes baseados no sistema peróxi-oxalato ${ }^{47-49}$ e acridina, ${ }^{50}$ têm sido empregados na determinação de fármacos. O mecanismo da quimiluminescência promovida pelo luminol é mostrado no Esquema 2. Neste caso, o luminol (5-amino-2,3-diidroftalazina-1,4-diona) reage com peróxido de hidrogênio na presença de íons hidroxila e um catalisador para formar um intermediário rico em energia (íon aminoftalato excitado) com subseqüente emissão de luz. ${ }^{50}$
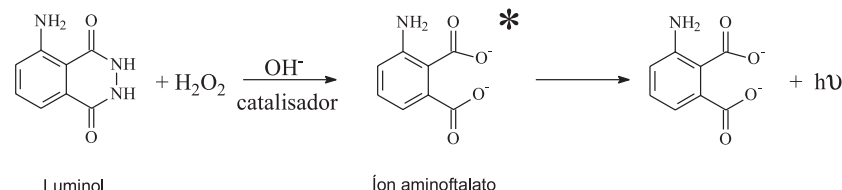

Esquema 2. Representação esquemática da geração de quimiluminescência do luminol na presença de peróxido de hidrogênio em meio básico

O sistema pode ser aplicado na quantificação de luminol e seus derivados, peróxido de hidrogênio ou algum catalisador da reação, como metais ${ }^{51}$ fármacos ${ }^{52}$ ou enzimas.

Métodos quimiluminescentes baseados no sistema peróxi-oxalato ${ }^{48}$ são considerados até o momento os processos não-enzimáticos com maior eficiência quântica. ${ }^{47,48,53} \mathrm{O}$ mecanismo pode ser explicado através da luminescência quimicamente iniciada por intercâmbio de elétrons ou CIEEL (chemically initiated electron exchange luminescence) ${ }^{47}$ Uma reação típica baseada neste tipo de quimiluminescência é mostrada no Esquema 3.

$$
\underset{\mathrm{ArO}^{\prime}}{\stackrel{\mathrm{O}}{\mathrm{O}}-\mathrm{C}_{-\mathrm{OAr}}^{\mathrm{O}}}+\mathrm{H}_{2} \mathrm{O}_{2} \underset{\text { ativador }}{\stackrel{\text { base }}{\longrightarrow}} 2 \mathrm{ArOH}+2 \mathrm{CO}_{2}+\mathrm{hv}
$$

Esquema 3. Reagentes e produtos do sistema peróxi-oxalato, usando um éster fenólico do ácido oxálico e peróxido de hidrogênio, na presença de um ativador em meio básico ${ }^{48,54}$

O Esquema 3 mostra a quimiluminescência obtida a partir de um éster fenólico de ácido oxálico e peróxido de hidrogênio, catalisada por base na presença de uma substância com rendimento quântico alto a qual é chamada, neste tipo de reações, de ativador. Estas reações são acompanhadas por uma forte emissão de luz, a qual é oriunda da fluorescência do ativador, ${ }^{48,54}$ resultando em sistemas luminescentes que superam àqueles baseados em luminol, e apresentam-se como ferramentas em potencial para serem aplicados na determinação de fármacos. ${ }^{49}$

Outros sistemas quimiluminescentes que eventualmente também podem ser empregados na determinação de fármacos incluem aqueles baseados nos derivados da acridina, tal como a lucigenina, cuja reação quimiluminescente é mostrada no Esquema 4.

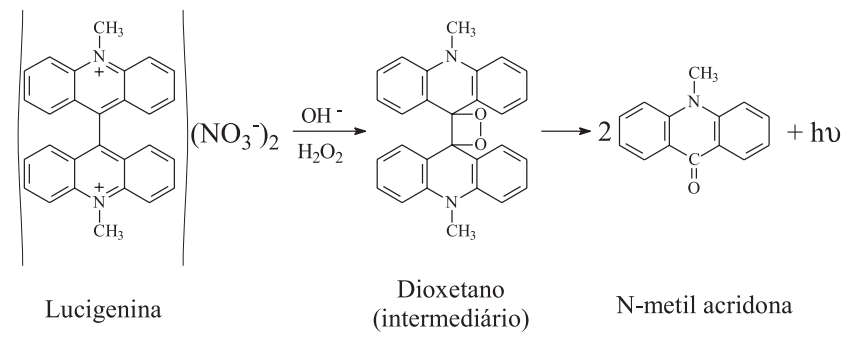

Esquema 4. Reação quimiluminescente para a lucigenina na presença de peróxido de hidrogênio e em meio alcalino. Mostram-se o intermediário chave e o produto da reaçã $o^{47}$
Analogamente ao luminol, derivados da acridina reagem com peróxido de hidrogênio em soluções alcalinas, produzindo intermediários excitados, seguidos por luminescência. Embora aplicações na determinação de fármacos ainda não tenham sido devidamente exploradas, este tipo de reações abre uma nova alternativa de aplicação.

Em termos gerais, as medidas da intensidade fotoluminescente ou quimiluminescente permitem a determinação quantitativa seletiva e sensível de uma variedade de espécies orgânicas e inorgânicas importantes, tais como princípios ativos de medicamentos e cosméticos, inclusive em níveis abaixo de $10^{-9} \mathrm{~mol} \mathrm{~L}^{-1}$. Atualmente, como é esperado, o número de métodos fluorimétricos descritos na literatura é significativamente superior ao número de aplicações de procedimentos fosforescentes e quimiluminescentes, próprio das características de cada um dos fenômenos luminescentes.

\section{APLICAÇÃO DA ESPECTROSCOPIA DE LUMINESCÊNCIA NO CAMPO FARMACÊUTICO}

A importância do controle químico de produtos farmacêuticos como resultado do impacto na saúde pública e socioeconômica demanda métodos analíticos sensíveis e confiáveis. Adicionalmente a estas exigências juntam-se aquelas que implicam o acompanhamento das análises em larga escala com altas velocidades de amostragem. Nos últimos anos, muitos grupos de pesquisas têm se dedicado ao desenvolvimento de novos métodos analíticos baseados na emissão de luminescência, dentre eles a quimilumi-nescência ${ }^{16,39,45,55-57}$ e fluorescência, ${ }^{12-17,19-22,58-135}$ no intuito de determinar diferentes fármacos em diversos tipos de preparações farmacêuticas.

As metodologias variam desde o aproveitamento da fluorescência nativa de alguns fármacos ${ }^{19,20,58-74,80,110-115,118-122,124,125,129,133-135}$ até o uso da quimiluminescência induzida por diversos reagentes. ${ }^{16,39,45,55-57}$

\section{Determinação de medicamentos baseada na fluorescência do princípio ativo}

A fluorescência nativa tem sido explorada para a quantificação de fármacos em medicamentos; com base nisto, muitos trabalhos têm sido descritos na literatura. . $^{192,58-74,80,110-115,118-122,124,125,129,133-135}$ A Tabela 1 mostra os principais fármacos determinados através da fluorescência nativa em solução.

A literatura destaca inúmeras variações das metodologias de análise que repercutem no aumento da intensidade fluorescente da molécula do fármaco, dentre elas destacam-se o uso de meio orgânico, ${ }^{69,71,119,120}$ ácido, ${ }^{65,68,69,72-74,122,124}$ básico, ${ }^{59-61}$ e até meios micelares usando tensoativos. ${ }^{66,67}$ Por exemplo, Manzoori e colaboradores ${ }^{67}$ reportaram a determinação de piroxicam em medicamentos, em soro sanguíneo e urina, a partir do aumento da intensidade de fluorescência nativa do fármaco em presença do surfactante dodecilsulfato de sódio (fase micelar) em meio ácido. Outros autores também têm relatado o emprego de tensoativos na determinação fluorescente de diversos fármacos..$^{89,92,100,130}$

O uso da calibração multivariada ${ }^{62,114,118-125}$ para resolução de sinais superpostos de misturas de fármacos fluorescentes também tem sido empregada. São relatados desde os métodos multivariados mais simples como PLS (partial least-squares regres-sion), ${ }^{62,114,118,119,121-123,125}$ PARAFAC (parallel factor analysis) e BLLS (Bilinear Least-Squares), ${ }^{124}$ até o uso de redes neurais mais sofisticadas como as redes de Kohonen ${ }^{120}$ (Tabela 1), cujo objetivo é conferir maior seletividade à metodologia, visando determinação dos fármacos em amostras complexas, como soro e urina.

Determinação de fármacos em fase sólida

Uma técnica recentemente explorada para determinação de fárma- 
Tabela 1. Determinação de fármacos com fluorescência nativa

\begin{tabular}{|c|c|c|c|c|c|c|}
\hline $\begin{array}{l}\text { Princípio } \\
\text { ativo }\end{array}$ & Classificação & $\begin{array}{l}\text { Metodologia empregada } \\
\text { para gerar luminescência }\end{array}$ & $\begin{array}{l}\text { Faixa de } \\
\text { análise }\end{array}$ & $\begin{array}{l}\text { Limite de } \\
\text { detecção }\end{array}$ & $\begin{array}{l}\text { Marca (forma farmacêutica) } \\
\text { e Fabricante }\end{array}$ & Ref. \\
\hline $\begin{array}{l}\text { Ácido } \\
\text { acetilsalicílico }\end{array}$ & $\begin{array}{l}\text { Analgésico } \\
\text { Antipirético }\end{array}$ & $\begin{array}{l}\text { Fluorescência nativa do } \\
\text { fármaco. } \lambda_{\text {exc }}=220 \mathrm{~nm} ; \\
\lambda_{\text { }}=408 \mathrm{~nm} .\end{array}$ & $\begin{array}{l}0,40-5,2 \\
\mathrm{mg} \mathrm{L}^{-1}\end{array}$ & $0,11 \mathrm{mg} \mathrm{L}^{-1}$ & Não determinado & 118 \\
\hline $\begin{array}{l}\text { Ácido } \\
\text { acetilsalicílico }\end{array}$ & $\begin{array}{l}\text { Analgésico } \\
\text { Antipirético }\end{array}$ & $\begin{array}{l}\text { Fluorescência nativa do } \\
\text { fármaco em solução de } \\
\text { clorofórmio contendo ácido } \\
\text { acético a } 1 \% . \lambda_{\text {exc }}=220 \mathrm{~nm} \text {; } \\
\lambda_{\text {em }}=330 \mathrm{~nm} \text {. Usando } \\
\text { calibracão multivariada. }\end{array}$ & $\begin{array}{l}2,0-12 \\
\mu \mathrm{g} \mathrm{mL}-1\end{array}$ & Não reportado & $\begin{array}{l}\text { Aspirina }{ }^{\circledR} \\
\text { (comprimido), Bayer }\end{array}$ & 119 \\
\hline $\begin{array}{l}\text { Ácido } \\
\text { flufenâmico }\end{array}$ & $\begin{array}{l}\text { Antiinfla- } \\
\text { matório }\end{array}$ & $\begin{array}{l}\text { Fluorescência nativa do } \\
\text { fármaco em clorofórmio. } \\
\lambda_{\text {exc }}=352 \mathrm{~nm} ; \lambda_{\mathrm{em}}=422 \mathrm{~nm} \text {. } \\
\text { Usando redes neurais } \\
\text { artificiais de Kohonen. }\end{array}$ & $\begin{array}{l}0,25-1,0 \\
\mu \mathrm{g} \mathrm{mL}-1\end{array}$ & Não informado & $\begin{array}{l}\text { Movisilin }{ }^{\circledR} \text { (não informado), } \\
\text { Sankyo Pharma }\end{array}$ & 120 \\
\hline $\begin{array}{l}\text { Ácido } \\
\text { mefenâmico }\end{array}$ & $\begin{array}{l}\text { Antiinfla- } \\
\text { matório }\end{array}$ & $\begin{array}{l}\text { Fluorescência nativa do } \\
\text { fármaco em clorofórmio. } \\
\lambda_{\mathrm{exc}}=352 \mathrm{~nm} ; \lambda_{\mathrm{em}}=449 \mathrm{~nm} . \\
\text { Usando redes neurais } \\
\text { artificiais de Kohonen. }\end{array}$ & $\begin{array}{l}1,0-4,0 \\
\mu g \mathrm{~mL}^{-1}\end{array}$ & Não informado & $\begin{array}{l}\text { Coslan }^{\circledR} \text { (cápsula), } \\
\text { Parke-Davis }\end{array}$ & 120 \\
\hline $\begin{array}{l}\text { Ácido } \\
\text { meclofenâmico }\end{array}$ & $\begin{array}{l}\text { Antiinfla- } \\
\text { matório }\end{array}$ & $\begin{array}{l}\text { Fluorescência nativa do } \\
\text { fármaco em clorofórmio. } \\
\lambda_{\text {exc }}=352 \mathrm{~nm} ; \lambda_{\mathrm{em}}=405 \mathrm{~nm} \text {. } \\
\text { Usando redes neurais } \\
\text { artificiais de Kohonen. }\end{array}$ & $\begin{array}{l}0,25-1,0 \\
\mu \mathrm{g} \mathrm{mL}-1\end{array}$ & Não informado & $\begin{array}{l}\text { Meclofen }^{\circledR} \text { (cápsula), } \\
\text { Parke-Davis }\end{array}$ & 120 \\
\hline Acrivastina & Antialérgico & $\begin{array}{l}\text { Fluorescência nativa do } \\
\text { fármaco em tampão acetato } \\
(\mathrm{pH} 6,5) . \lambda_{\mathrm{exc}}=230 \mathrm{~nm} ; \\
\lambda_{\mathrm{em}}=380 \mathrm{~nm} .\end{array}$ & $\begin{array}{l}58-2000 \\
n g \mathrm{~mL}^{-1}\end{array}$ & $23 \mathrm{ng} \mathrm{mL}^{-1}$ & $\begin{array}{l}\text { Semprex-D }{ }^{\circledR} \text { (cápsulas), } \\
\text { Glaxo-Wellcome }\end{array}$ & 58 \\
\hline Bromazepan & Ansiolítico & $\begin{array}{l}\text { Fluorescência nativa do } \\
\text { fármaco em solução } \\
\text { metanólica de hidróxido de } \\
\text { potássio. } \lambda_{\text {exc }}=260 \mathrm{~nm} ; \\
\lambda_{\text {em }}=570 \mathrm{~nm} .\end{array}$ & $\begin{array}{l}0,03-0,32 \\
\mu \mathrm{g} \mathrm{mL}-1\end{array}$ & $5,7 \mathrm{ng} \mathrm{mL}^{-1}$ & $\begin{array}{l}\text { Calmepan } ® \text { (comprimido), } \\
\text { não informado }\end{array}$ & 59 \\
\hline Bumetanida & Diurético & $\begin{array}{l}\text { Fluorescência nativa do } \\
\text { fármaco em NaOH } 0,001 \\
\text { mol L } L^{-1} \text {, empregando sistema } \\
\text { de injeção em fluxo. } \\
\lambda_{\text {exc }}=314 \mathrm{~nm} ; \lambda_{\mathrm{em}}=370 \mathrm{~nm} .\end{array}$ & $\begin{array}{l}0,05- \\
10,0 \mu \mathrm{g} \mathrm{mL}-1\end{array}$ & $0,01 \mu \mathrm{g} \mathrm{mL}^{-1}$ & $\begin{array}{l}\text { Burinex }^{\circledR} \text { (comprimido), } \\
\text { LEO Pharmaceutical Product } \\
\text { Burinex }{ }^{\circledR} \text { (injeção), } \\
\text { LEO Pharmaceutical Product }\end{array}$ & 60 \\
\hline Cetoconazol & Antimicótico & $\begin{array}{l}\text { Fluorescência nativa do } \\
\text { fármaco em solução tampão } \\
\text { de Teorrel e Stenhagen } \\
(\mathrm{pH} 10,0) . \lambda_{\mathrm{exc}}=288 \mathrm{~nm} \\
\lambda_{\mathrm{em}}=375 \mathrm{~nm}\end{array}$ & $\begin{array}{l}49,7-800 \\
\mathrm{ng} \mathrm{mL}\end{array}$ & $14,9 \mathrm{ng} \mathrm{mL}^{-1}$ & $\begin{array}{l}\text { Cetoconazol (pó), } \\
\text { Janseen Pharmaceutical } \\
\text { Cetoconazol (creme), } \\
\text { Janseen Pharmaceutical }\end{array}$ & 61 \\
\hline Ciprofloxacina & Antibiótico & $\begin{array}{l}\text { Fluorescência nativa em meio } \\
\text { ácido ( } \mathrm{pH} 4,0 \text { ). Emprego de } \\
\text { métodos de calibração multi- } \\
\text { variada (PARAFAC e BLLS). }\end{array}$ & $\begin{array}{l}0-200 \\
\mu g \mathrm{~L}^{-1}\end{array}$ & $2 \mu \mathrm{g} \mathrm{L}^{-1}$ & $\begin{array}{l}\text { Aplicado em análise } \\
\text { de urina. }\end{array}$ & 124 \\
\hline Clonazepam & $\begin{array}{l}\text { Sedativo } \\
\text { Anticonvul- } \\
\text { sivo }\end{array}$ & $\begin{array}{l}\text { Fluorescência nativa do } \\
\text { fármaco em solução } \\
\text { metanólica de hidróxido de } \\
\text { potássio. } \lambda_{\text {exc }}=368 \mathrm{~nm} ; \\
\lambda_{\text {em }}=425 \mathrm{~nm} .\end{array}$ & $\begin{array}{l}0,03-0,38 \\
\mu \mathrm{g} \mathrm{mL}-1\end{array}$ & $16,5 \mathrm{ng} \mathrm{mL}^{-1}$ & $\begin{array}{l}\text { Rivotril }^{\circledR} \text { (comprimido), } \\
\text { não informado }\end{array}$ & 59 \\
\hline Codeína & $\begin{array}{l}\text { Antitussígeno } \\
\text { Analgésico }\end{array}$ & $\begin{array}{l}\text { Fluorescência nativa do } \\
\text { fármaco. } \lambda_{\mathrm{exc}}=220 \mathrm{~nm} ; \\
\lambda_{\mathrm{em}}=350 \mathrm{~nm}\end{array}$ & $\begin{array}{l}0,05-0,25 \\
\mathrm{mg} \mathrm{L}^{-1}\end{array}$ & $0,04 \mathrm{mg} \mathrm{L}^{-1}$ & Não determinado & 118 \\
\hline Codeína & $\begin{array}{l}\text { Antitussígeno } \\
\text { Analgésico }\end{array}$ & $\begin{array}{l}\text { Fluorescência nativa do } \\
\text { fármaco em tampão fosfato } \\
\text { pH } 7,0 . \lambda_{\text {exc }}=220 \mathrm{~nm} ; \\
\lambda_{\text {em }}=350 \mathrm{~nm} \text {. Usando } \\
\text { calibração multivariada. }\end{array}$ & $\begin{array}{l}0,25-3,0 \\
\mathrm{mg} \mathrm{L}^{-1}\end{array}$ & Não reportado & $\begin{array}{l}\text { Codeisán }{ }^{\circledR} \text { (comprimido), } \\
\text { não informado } \\
\text { Codeína Perduretas }^{\circledR} \\
\text { (comprimido), } \\
\text { não informado }\end{array}$ & 121 \\
\hline
\end{tabular}


Tabela 1. continuação

\begin{tabular}{|c|c|c|c|c|c|c|}
\hline $\begin{array}{l}\text { Princípio } \\
\text { ativo }\end{array}$ & Classificação & $\begin{array}{l}\text { Metodologia empregada } \\
\text { para gerar luminescência }\end{array}$ & $\begin{array}{l}\text { Faixa de } \\
\text { análise }\end{array}$ & $\begin{array}{l}\text { Limite de } \\
\text { detecção }\end{array}$ & $\begin{array}{l}\text { Marca (forma farmacêutica) } \\
\text { e Fabricante }\end{array}$ & Ref. \\
\hline Diazepam & Ansiolítico & $\begin{array}{l}\text { Fluorescência nativa em } \\
\text { solução metanólica de } \\
\text { hidróxido de potássio. } \\
\lambda_{\text {exc }}=380 \mathrm{~nm} ; \lambda_{\text {em }}=454 \mathrm{~nm} .\end{array}$ & $\begin{array}{l}0,03-0,34 \\
\mu \mathrm{g} \mathrm{mL}-1\end{array}$ & $7,1 \mathrm{ng} \mathrm{mL}^{-1}$ & $\begin{array}{l}\text { Valium }{ }^{\circledast} \text { (comprimido), } \\
\text { não informado }\end{array}$ & 59 \\
\hline Efedrina & $\begin{array}{l}\text { Descongestio- } \\
\text { nante nasal e } \\
\text { tratamento de } \\
\text { asma }\end{array}$ & $\begin{array}{l}\text { Fluorescência nativa do } \\
\text { fármaco. } \lambda_{\mathrm{exc}}=220 \mathrm{~nm} ; \\
\lambda_{\mathrm{em}}=287 \mathrm{~nm}\end{array}$ & $\begin{array}{l}0,80-8,0 \\
\mathrm{mg} \mathrm{L}^{-1}\end{array}$ & $0,33 \mathrm{mg} \mathrm{L}^{-1}$ & Não determinado & 118 \\
\hline$\alpha$-Estradiol & Estrógeno & $\begin{array}{l}\text { Fluorescência nativa do } \\
\text { fármaco. } \lambda_{\mathrm{exc}}=285 \mathrm{~nm} ; \\
\lambda_{\mathrm{eq}}=310 \mathrm{~nm} .\end{array}$ & $\begin{array}{l}1,5-25 \\
\mu g \mathrm{~mL}^{-1}\end{array}$ & $0,13 \mu \mathrm{g} \mathrm{mL}^{-1}$ & Não determinado & 134 \\
\hline Fenilefrina & $\begin{array}{l}\text { Descongestio- } \\
\text { nante nasal }\end{array}$ & $\begin{array}{l}\text { Aproveitamento da fluores- } \\
\text { cência nativa, } \lambda_{\mathrm{exc}}=277 \mathrm{~nm} ; \\
\lambda_{\mathrm{em}}=300 \mathrm{~nm} . \text { Emprego de } \\
\text { calibração multivariada. }\end{array}$ & $\begin{array}{l}0,8-2,0 \\
\mathrm{mg} \mathrm{L}^{-1}\end{array}$ & $0,08 \mathrm{mg} \mathrm{L}^{-1}$ & $\begin{array}{l}\text { Wagner }{ }^{\circledR} \text { (comprimido), } \\
\text { não informado } \\
\text { Tabein }{ }^{\circledR} \text { (comprimido), } \\
\text { não informado } \\
\text { Dristan }{ }^{\circledR} \text { (comprimido), } \\
\text { não informado } \\
\text { Wilpan }{ }^{\circledR} \text { (comprimido), } \\
\text { não informado }\end{array}$ & 62 \\
\hline Furosemida & Diurético & $\begin{array}{l}\text { Emprego da espectrometria } \\
\text { de fluorescência de varredura } \\
\text { de ângulo variável em mistura } \\
\text { de vários diuréticos, aprovei- } \\
\text { tando a fluorescência nativa } \\
\text { do fármaco. }\end{array}$ & $\begin{array}{l}10- \\
40 \mu \mathrm{g} \mathrm{mL}\end{array}$ & Não relatado & $\begin{array}{l}\text { Seguril }^{\circledR} \text { (comprimido), } \\
\text { Hoechst }\end{array}$ & 129 \\
\hline Furosemida & Diurético & $\begin{array}{l}\text { Fluorescência nativa do } \\
\text { fármaco em tampão tartrato } \\
(\mathrm{pH} 2,5) . \lambda_{\mathrm{exc}}=270 \mathrm{~nm} ; \\
\lambda_{\mathrm{em}}=410 \mathrm{~nm} \text {. Aplicando } \\
\text { calibração multivariada. }\end{array}$ & $\begin{array}{l}0,212-1,06 \\
\mu \mathrm{g} \mathrm{mL}-1\end{array}$ & Não informado & $\begin{array}{l}\text { Salidur }^{\circledR} \text { (comprimido), } \\
\text { não informado } \\
\text { Seguril }^{\circledR} \text { (comprimido), } \\
\text { não informado }\end{array}$ & 122 \\
\hline Ibuprofeno & $\begin{array}{l}\text { Antiinflama- } \\
\text { tório } \\
\text { Antipirético } \\
\text { Analgésico }\end{array}$ & $\begin{array}{l}\text { Fluorescência nativa do } \\
\text { fármaco em hidróxido de } \\
\text { sódio } 0,05 \mathrm{~mol} \mathrm{~L}^{-1} \text {. } \\
\lambda_{\mathrm{exc}}=224 \mathrm{~nm} ; \lambda_{\mathrm{em}}=290 \mathrm{~nm} .\end{array}$ & $\begin{array}{l}0,4-2,4 \\
\mathrm{mg} \mathrm{L}^{-1}\end{array}$ & $0,2 \mathrm{mg} \mathrm{L}^{-1}$ & $\begin{array}{l}\text { Ibuprofeno (comprimido), } \\
\text { não informado }\end{array}$ & 63 \\
\hline Isoxsuprina & Vasodilatador & $\begin{array}{l}\text { Fluorescência nativa do } \\
\text { fármaco em água destilada. } \\
\lambda_{\mathrm{exc}}=270 \mathrm{~nm} ; \lambda_{\mathrm{em}}=305 \mathrm{~nm} \text {. }\end{array}$ & $\begin{array}{l}0,4-4,0 \\
\mu \mathrm{g} \mathrm{mL}-1\end{array}$ & $0,11 \mu \mathrm{g} \mathrm{mL}^{-1}$ & $\begin{array}{l}\text { Duvadilan }^{\circledR} \text { (comprimido), } \\
\text { Solvay Duphar B.V. }\end{array}$ & 64 \\
\hline Mivacurio & $\begin{array}{l}\text { Agente } \\
\text { bloqueador } \\
\text { neuromuscular }\end{array}$ & $\begin{array}{l}\text { Fluorescência nativa do } \\
\text { fármaco em solução tampão } \\
\text { acetato }(\mathrm{pH} 5,5) \lambda_{\mathrm{exc}}=230 \mathrm{~nm} \text {; } \\
\lambda_{\mathrm{em}}=324 \mathrm{~nm} .\end{array}$ & $\begin{array}{l}5-500 \\
\text { ng } \mathrm{mL}^{-1}\end{array}$ & $0,93 \mathrm{ng} \mathrm{mL}^{-1}$ & $\begin{array}{l}\text { Mivacrom }^{\circledR} \text { (injeção), } \\
\text { Glaxo-Wellcome }\end{array}$ & 65 \\
\hline Moxifloxacina & Antibiótico & $\begin{array}{l}\text { Fluorescência nativa do } \\
\text { fármaco em tampão fosfato } \\
(\mathrm{pH} 8,3) . \lambda_{\mathrm{exc}}=287 \mathrm{~nm} \\
\lambda_{\mathrm{em}}=465 \mathrm{~nm}\end{array}$ & $\begin{array}{l}30-300 \\
\mathrm{ng} \mathrm{mL}\end{array}$ & $10 \mathrm{ng} \mathrm{mL}^{-1}$ & $\begin{array}{l}\text { Octegra }^{\circledR} \text { (comprimido), } \\
\text { não informado } \\
\text { Actira }^{\circledR} \text { (comprimido), } \\
\text { não informado } \\
\text { Proflox }{ }^{\circledR} \text { (comprimido), } \\
\text { não informado }\end{array}$ & 66 \\
\hline Naproxeno & $\begin{array}{l}\text { Antiinflama- } \\
\text { tório }\end{array}$ & $\begin{array}{l}\text { Fluorescência nativa do } \\
\text { fármaco em solução de } \\
\text { clorofórmio contendo ácido } \\
\text { acético a } 1 \%(\mathrm{v} / \mathrm{v}) . \\
\lambda_{\text {exc }}=220 \mathrm{~nm} ; \lambda_{\text {em }}=360 \mathrm{~nm} \text {. } \\
\text { Usando calibração } \\
\text { multivariada. }\end{array}$ & $\begin{array}{l}0,1-1,0 \\
\mu \mathrm{g} \mathrm{mL}-1\end{array}$ & Não reportado & $\begin{array}{l}\text { Naproxin }^{\circledR} \text { (comprimido), } \\
\text { Roche S.A. }\end{array}$ & 119 \\
\hline Naproxeno & $\begin{array}{l}\text { Antiinflama- } \\
\text { tório } \\
\text { Analgésico }\end{array}$ & $\begin{array}{l}\text { Fluorescência nativa do } \\
\text { fármaco em hidróxido de } \\
\text { sódio } 0,05 \mathrm{~mol} \mathrm{~L}^{-1} \text {. } \\
\lambda_{\text {exc }}=230 \mathrm{~nm} ; \lambda_{\mathrm{em}}=355 \mathrm{~nm} .\end{array}$ & $\begin{array}{l}5,0-20 \\
\mu g \mathrm{~L}^{-1}\end{array}$ & $0,9 \mu \mathrm{g} \mathrm{L}^{-1}$ & $\begin{array}{l}\text { Naprosyn }^{\circledR} \text { (comprimido), } \\
\text { não informado }\end{array}$ & 63 \\
\hline
\end{tabular}


Tabela 1. continuação

\begin{tabular}{|c|c|c|c|c|c|c|}
\hline $\begin{array}{l}\text { Princípio } \\
\text { ativo }\end{array}$ & Classificação & $\begin{array}{l}\text { Metodologia empregada } \\
\text { para gerar luminescência }\end{array}$ & $\begin{array}{l}\text { Faixa de } \\
\text { análise }\end{array}$ & $\begin{array}{l}\text { Limite de } \\
\text { detecção }\end{array}$ & $\begin{array}{l}\text { Marca (forma farmacêutica) } \\
\text { e Fabricante }\end{array}$ & Ref. \\
\hline Piretamida & Diurético & $\begin{array}{l}\text { Emprego da espectrometria } \\
\text { de fluorescência de varredura } \\
\text { de ângulo variável em mistura } \\
\text { de vários diuréticos, aprovei- } \\
\text { tando a fluorescência nativa } \\
\text { do fármaco. }\end{array}$ & $\begin{array}{l}1,0-10 \\
\mu \mathrm{g} \mathrm{mL}-1\end{array}$ & Não relatado & $\begin{array}{l}\text { Perbilen }^{\circledR} \text { (cápsulas), } \\
\text { Hoechst }\end{array}$ & 129 \\
\hline Piridoxina & Vitamina B & $\begin{array}{l}\text { Fluorescência nativa do } \\
\text { fármaco em tampão fosfato } \\
\mathrm{pH} 7,0 . \lambda_{\mathrm{exc}}=220 \mathrm{~nm} \\
\lambda_{\mathrm{em}}=390 \mathrm{~nm} \text {. Usando } \\
\text { calibração multivariada. }\end{array}$ & $\begin{array}{l}0,10-2,0 \\
\mathrm{mg} \mathrm{L}^{-1}\end{array}$ & Não relatado & $\begin{array}{l}\text { Benadom }^{\circledR} \text { (comprimido), } \\
\text { não informado }\end{array}$ & 121 \\
\hline Piroxicam & $\begin{array}{l}\text { Antiinflama- } \\
\text { tório }\end{array}$ & $\begin{array}{l}\text { Fluorescência nativa do } \\
\text { fármaco aumentada na } \\
\text { presença do surfactante } \\
\text { dodecil sulfato de sódio em } \\
\text { meio ácido. } \lambda_{\text {exc }}=340 \mathrm{~nm} ; \\
\lambda_{\mathrm{em}}=460 \mathrm{~nm} .\end{array}$ & $\begin{array}{l}0,05-1,5 \\
\mu \mathrm{g} \mathrm{mL}-1\end{array}$ & $0,015 \mu \mathrm{g} \mathrm{mL}^{-1}$ & $\begin{array}{l}\text { Não informado (cápsulas), } \\
\text { não informado } \\
\text { Não informado (gel), } \\
\text { não informado }\end{array}$ & 67 \\
\hline Piroxicam & $\begin{array}{l}\text { Antiinflama- } \\
\text { tório }\end{array}$ & $\begin{array}{l}\text { Fluorescência nativa do } \\
\text { fármaco em meio de } \mathrm{HNO}_{3} \\
0,5 \mathrm{~mol} \mathrm{~L} \cdot \lambda_{\mathrm{exc}}=330 \mathrm{~nm} ; \\
\lambda_{\mathrm{em}}=440 \mathrm{~nm} .\end{array}$ & $\begin{array}{l}0,01-1,25 \\
\mu \mathrm{g} \mathrm{mL}-1\end{array}$ & Não relatado & $\begin{array}{l}\text { Não informado (cápsula), } \\
\text { não informado }\end{array}$ & 68 \\
\hline Piroxicam & $\begin{array}{l}\text { Antiinflama- } \\
\text { tório }\end{array}$ & $\begin{array}{l}\text { Fluorescência nativa do } \\
\text { fármaco em meio de } \mathrm{H}_{2} \mathrm{SO}_{4} \\
0,05 \mathrm{~mol} \mathrm{~L}^{-1} \cdot \lambda_{\mathrm{exc}}=345 \mathrm{~nm} ; \\
\lambda_{\mathrm{em}}=470 \mathrm{~nm} .\end{array}$ & $\begin{array}{l}0,20-2,0 \\
\mu \mathrm{g} \mathrm{mL}^{-1}\end{array}$ & $0,113 \mu \mathrm{g} \mathrm{mL}^{-1}$ & $\begin{array}{l}\text { Feldene }^{\circledR} \text { (injeção), } \\
\text { Pfizer-Egypt }\end{array}$ & 69 \\
\hline Piroxicam & $\begin{array}{l}\text { Antiinflama- } \\
\text { tório }\end{array}$ & $\begin{array}{l}\text { Fluorescência nativa do } \\
\text { fármaco em meio orgânico } \\
\text { de dioxano. } \lambda_{\mathrm{exc}}=340 \mathrm{~nm} ; \\
\lambda_{\mathrm{em}}=470 \mathrm{~nm} .\end{array}$ & $\begin{array}{l}0,20- \\
1,2 \mu \mathrm{g} \mathrm{mL}-1\end{array}$ & $0,150 \mu \mathrm{g} \mathrm{mL}^{-1}$ & $\begin{array}{l}\text { Feldene }^{\circledR} \text { (comprimido), } \\
\text { Pfizer-Egypt }\end{array}$ & 69 \\
\hline Ritrodina & $\begin{array}{l}\text { Agente simpa- } \\
\text { tomimético }\end{array}$ & $\begin{array}{l}\text { Fluorescência nativa do } \\
\text { fármaco. } \lambda_{\mathrm{exc}}=278 \mathrm{~nm} ; \\
\lambda_{\mathrm{em}}=308 \mathrm{~nm}\end{array}$ & $\begin{array}{l}4,0-9,0 \\
\mu g \mathrm{~mL}^{-1}\end{array}$ & $0,16 \mu \mathrm{g} \mathrm{mL}^{-1}$ & $\begin{array}{l}\text { Yutopar }^{\circledR} \text { (comprimido), } \\
\text { não informado } \\
\text { Ritodrina }{ }^{\circledR} \text { (ampolas), } \\
\text { Pharco Pharmaceuticals }\end{array}$ & 80 \\
\hline Salicilato & $\begin{array}{l}\text { Antiinflamató- } \\
\text { rio, analgésico, } \\
\text { antipirético }\end{array}$ & $\begin{array}{l}\text { Fluorescência nativa do } \\
\text { fármaco. } \lambda_{\mathrm{exc}}=297 \mathrm{~nm} ; \\
\lambda_{\mathrm{em}}=405 \mathrm{~nm}\end{array}$ & $\begin{array}{l}0,010-0,250 \\
\mu \mathrm{g} \mathrm{mL}-1\end{array}$ & $3 \mathrm{ng} \mathrm{mL}^{-1}$ & $\begin{array}{l}\text { Aplicado em análise } \\
\text { de soro. }\end{array}$ & 70 \\
\hline Salicilato & $\begin{array}{l}\text { Antiinflamató- } \\
\text { rio, analgésico, } \\
\text { antipirético }\end{array}$ & $\begin{array}{l}\text { Fluorescência nativa do } \\
\text { fármaco em solução de } \\
\text { clorofórmio contendo ácido } \\
\text { acético a } 1 \% . \lambda_{\text {exc }}=220 \mathrm{~nm} \text {; } \\
\lambda_{\text {em }}=450 \mathrm{~nm} \text {. Usando } \\
\text { calibração multivariada. }\end{array}$ & $\begin{array}{l}0,5-5 \\
\mu g \mathrm{~mL}^{-1}\end{array}$ & Não relatado & Não informado & 119 \\
\hline Salsalato & $\begin{array}{l}\text { Antiinflama- } \\
\text { tório }\end{array}$ & $\begin{array}{l}\text { Fluorescência nativa do } \\
\text { fármaco em meio orgânico } \\
\text { de clorofórmio e pirrolidina. } \\
\lambda_{\mathrm{exc}}=299 \mathrm{~nm} ; \lambda_{\mathrm{em}}=410 \mathrm{~nm} \text {. }\end{array}$ & $\begin{array}{l}0,10-1,0 \\
\mu \mathrm{g} \mathrm{mL}^{-1}\end{array}$ & $0,017 \mu \mathrm{g} \mathrm{mL}^{-1}$ & $\begin{array}{l}\text { Umbradol }^{\circledR} \text { (pó), } \\
\text { não informado } \\
\text { Não informado (cápsulas), } \\
\text { não informado }\end{array}$ & 71 \\
\hline Tacrina & $\begin{array}{l}\text { Tratamento } \\
\text { de carcinoma }\end{array}$ & $\begin{array}{l}\text { Fluorescência nativa do } \\
\text { fármaco em tampão acetato } \\
(\mathrm{pH} 5,6) . \lambda_{\mathrm{exc}}=242 \mathrm{~nm} ; \\
\lambda_{\mathrm{em}}=362 \mathrm{~nm} .\end{array}$ & $\begin{array}{l}1-70 \\
\mathrm{ng} \mathrm{mL}\end{array}$ & $0,24 \mathrm{ng} \mathrm{mL}^{-1}$ & $\begin{array}{l}\text { Cognex }^{\circledR} \text { (cápsula), } \\
\text { não informado }\end{array}$ & 72 \\
\hline $\begin{array}{l}\text { Tartrato de } \\
\text { ergotamina }\end{array}$ & Sedativo & $\begin{array}{l}\text { Fluorescência nativa do } \\
\text { fármaco em ácido clorídrico } \\
0,1 \text { mol } \mathrm{L}^{-1} \text {, em sistema de } \\
\text { fluxo seqüencial. } \\
\lambda_{\mathrm{exc}}=236 \mathrm{~nm} ; \lambda_{\mathrm{em}}=390 \mathrm{~nm} .\end{array}$ & $\begin{array}{l}0,03-0,61 \\
\mathrm{mg} \mathrm{L}^{-1}\end{array}$ & $0,01 \mathrm{mg} \mathrm{L}^{-1}$ & $\begin{array}{l}\text { Bellaspon }^{\circledR} \text { (comprimido), } \\
\text { Leciva A.S. }\end{array}$ & 73 \\
\hline Tenoxicam & $\begin{array}{l}\text { Antiinflamató- } \\
\text { rio } \\
\text { Analgésico }\end{array}$ & $\begin{array}{l}\text { Fluorescência nativa do } \\
\text { fármaco em ácido nítrico } \\
0,5 \mathrm{~mol} \mathrm{~L} \cdot \lambda_{\text {exc }}=350 \mathrm{~nm} ; \\
\lambda_{\mathrm{em}}=450 \mathrm{~nm} .\end{array}$ & $\begin{array}{l}40-200 \\
\mathrm{ng} \mathrm{mL}\end{array}$ & $11 \mathrm{ng} \mathrm{mL}^{-1}$ & $\begin{array}{l}\text { Epicotil }^{\circledR} \text { (comprimido), } \\
\text { não informado } \\
\text { Epicotil }^{\circledR} \text { (supositório), } \\
\text { não informado } \\
\text { Epicotil }^{\circledR} \text { (pó liofilizado), } \\
\text { não informado }\end{array}$ & 74 \\
\hline
\end{tabular}


Tabela 1. continuação

\begin{tabular}{|c|c|c|c|c|c|c|}
\hline $\begin{array}{l}\text { Princípio } \\
\text { ativo }\end{array}$ & Classificação & $\begin{array}{l}\text { Metodologia empregada } \\
\text { para gerar luminescência }\end{array}$ & $\begin{array}{l}\text { Faixa de } \\
\text { análise }\end{array}$ & $\begin{array}{l}\text { Limite de } \\
\text { detecção }\end{array}$ & $\begin{array}{l}\text { Marca (forma farmacêutica) } \\
\text { e Fabricante }\end{array}$ & Ref. \\
\hline Tenoxicam & $\begin{array}{l}\text { Antiinflama- } \\
\text { tório } \\
\text { Analgésico }\end{array}$ & $\begin{array}{l}\text { Fluorescência nativa do } \\
\text { fármaco em meio orgânico } \\
\text { de dioxano. } \lambda_{\mathrm{exc}}=360 \mathrm{~nm} \text {; } \\
\lambda_{\mathrm{em}}=480 \mathrm{~nm} .\end{array}$ & $\begin{array}{l}0,3-2,4 \\
\mu g \mathrm{~mL}^{-1}\end{array}$ & $0,137 \mu \mathrm{g} \mathrm{mL}^{-1}$ & $\begin{array}{l}\text { Epicotil }^{\circledR} \text { (comprimido), } \\
\text { IPICO } \\
\text { Epicotil }^{\circledR} \text { (pó liofilizado), } \\
\text { IPICO }\end{array}$ & 69 \\
\hline Triamtereno & Diurético & $\begin{array}{l}\text { Emprego da espectrometria } \\
\text { de fluorescência de varre- } \\
\text { dura de ângulo variável em } \\
\text { mistura de vários diuréticos, } \\
\text { aproveitando a fluorescência } \\
\text { nativa do fármaco. }\end{array}$ & $\begin{array}{l}50-150 \\
\mathrm{ng} \mathrm{mL}^{-1}\end{array}$ & Não relatado & $\begin{array}{l}\text { Triniagar }^{\circledR} \text { (comprimido), } \\
\text { Farmasimes }\end{array}$ & 129 \\
\hline Triamtereno & Diurético & $\begin{array}{l}\text { Fluorescência nativa do } \\
\text { fármaco em tampão tartrato } \\
(\mathrm{pH} 2,5) . \lambda_{\mathrm{exc}}=360 \mathrm{~nm} \text {; } \\
\lambda_{\mathrm{em}}=438 \mathrm{~nm} \text {. Aplicando } \\
\text { calibração multivariada. }\end{array}$ & $\begin{array}{l}0,0204-0,143 \\
\mu g \mathrm{~mL}^{-1}\end{array}$ & Não informado & $\begin{array}{l}\text { Salidur }^{\circledR} \text { (comprimido), } \\
\text { não informado }\end{array}$ & 122 \\
\hline
\end{tabular}

cos em medicamentos tem sido a quantificação da fluorescência em fase sólida (Tabela 2). Esta técnica tem demonstrado vantagens na redução do consumo de reagentes e geração de resíduos. Outra vantagem é o ganho obtido na intensidade de luminescência, uma vez que em fase sólida a molécula se encontra com uma estrutura mais rígida quando comparada em solução, evitando com isto perdas da intensidade luminescente por processos paralelos de desativação (Figura 1S).

A espectroscopia de luminescência em fase sólida para compostos que possuem fluorescência nativa ainda tem sido muito pouco explorada, ${ }^{19,20,70,112-115,125,133,135}$ apesar das várias vantagens que este tipo de aplicação pode oferecer. Adicionalmente, podem ser realizadas análises não-destrutivas, seguindo a tendência atual em direção à Química Limpa, bem como análises on-line e/ou in situ. Outra vantagem ao induzir luminescência diretamente na matriz da amostra diz respeito à eliminação de reações paralelas capazes de suprimir a luminescência, as quais comumente podem ocorrer em solução, e têm limitado a aplicação da espectroscopia de fluorescência na determinação de muitos analitos.

Recentemente, trabalhos empregando a quantificação de luminescência diretamente nas amostras sólidas, tal como comercializadas (comprimidos e cápsulas sob a forma de partículas sólidas finamente pulverizadas), têm sido descritos na literatura por Moreira e colaboradores $^{19,20,125,133}$ (Tabela 2); os mesmos demonstraram a viabilidade e vantagens inerentes que este tipo de análise oferece, tais como simplicidade, rapidez, nenhuma geração de resíduos, nenhum preparo de soluções, nem pré-tratamento de amostra. Essas características tornam a espectrofluorimetria em fase sólida uma ferramenta bastante promissora para o controle de qualidade, quantificação e identificação de medicamentos com baixa solubilidade, como o ibuprofeno, ${ }^{97,136}$ possibilitando ainda avaliar interações reais entre o princípio ativo e os excipientes diretamente na matriz oriunda do fármaco.

Uma contribuição extremamente importante dos trabalhos descritos por Moreira e colaboradores é o fato de terem encontrado propriedades luminescentes em moléculas quando em estado sólido, as quais em solução aparentemente não apresentavam luminescência. ${ }^{20}$ Este fato abre um precedente para investigar as propriedades luminescentes de fármacos em fase sólida, que até agora, em solução, não apresentaram luminescência.

\section{Complexos fluorescentes de fármacos}

No intuito de obter um sinal fluorescente, a formação de complexos entre o fármaco e outras espécies tem sido bastante explorada por muitos grupos de pesquisa ${ }^{15,74,78,94-110,117,132}$ (Tabela 3)

Muitos artigos têm demonstrado que a inclusão do fármaco dentro da cavidade de ciclodextrinas pode induzir a emissão de várias moléculas. ${ }^{94-99,102,117}$ Este fato é explicado principalmente pela rigidez adicional à qual a molécula de fármaco é submetida. Outra vantagem deste tipo de complexos é que podem ser determinados fármacos que são insolúveis em meio aquoso, pois as ciclodextrinas fornecem simultaneamente sítios de ligação hidrofílicos e hidrofóbicos, estes últimos servindo para inclusão da molécula de fármaco, formando complexos do tipo hóspede-hospedeiro, como são conhecidos.

Complexos ternários formados na presença de íon térbio (III), o fármaco, e moléculas de óxido de trioctilfosfina ${ }^{100}$ ou moléculas de tris-hidroximetilaminoetano (TRIS), ${ }^{101}$ ou EDTA em meio alcalino ${ }^{103}$ também oferecem uma forma de quantificar alguns fármacos em formulações comerciais.

A capacidade que possuem alguns fármacos derivados de quinolonas e quinolinas para formar com metais de transição complexos fluorescentes tem sido explorada na determinação desses reagentes fluorogênicos (fármacos). Assim, quelatos desta família de fármacos com diversos metais de transição como zircônio, molibdênio, vanádio, tungstênio ${ }^{104}$ e alumínio ${ }^{107,108}$ têm sido descritos na literatura.

É bastante conhecido que quelatos orgânicos de íons lantanídeos exibem propriedades espectroscópicas bastantes peculiares. Enquanto seus espectros de absorção apresentam o perfil esperado para os respectivos complexos orgânicos, seus espectros de emissão são bandas extremamente estreitas características das transições $4 f$ dentro dos íons lantanídeos. ${ }^{106,132}$ Este fenômeno conhecido como luminescência sensibilizada por lantanídeos ${ }^{5,130-132,137}$ pode ser explicado como sendo devido à transferência de energia intramolecular desde o nível tripleto mais baixo do complexo para um nível $4 f$ do íon, resultando em uma mudança notória de espectros de bandas largas de excitação para uma banda estreita de emissão. ${ }^{132}$ Isto tem sido bastante utilizado para determinação de fármacos em preparações farmacêuticas. ${ }^{5,78,105,106,130-132}$ Nestes casos o íon mais empregado é o Eu(III), e baseia-se no comportamento espectroscópico do complexo Fármaco-Eu(III), no qual o fármaco, após absorver fortemente radiação eletromagnética a um comprimento de onda característico, transfere esta radiação para o íon $\mathrm{Eu}(\mathrm{III})$, resultando em um pico de emissão atômica estreito e intenso, característico da emissão do íon lantanídeo a $615 \mathrm{~nm}$. Deste modo, o pico de emissão atômico do Eu(III) aparece em uma região espectral distante da possível interferência da matriz. ${ }^{137}$ Adicionalmente, pesquisas demonstraram que a intensidade da fluorescência em meios micelares de tensoativos não-iônicos é grandemente amplificada, 5,130 
Tabela 2. Determinação de fármacos com fluorescência nativa em fase sólida

\begin{tabular}{llllll}
\hline $\begin{array}{l}\text { Princípio } \\
\text { ativo }\end{array}$ & Classificação & $\begin{array}{l}\text { Metodologia empregada } \\
\text { para gerar luminescência }\end{array}$ & $\begin{array}{l}\text { Faixa de } \\
\text { análise }\end{array}$ & $\begin{array}{l}\text { Limite de } \\
\text { detecção }\end{array}$ & $\begin{array}{l}\text { Marca (forma farmacêutica) } \\
\text { e Fabricante }\end{array}$ \\
\hline $\begin{array}{l}\text { Ácido } \\
\text { acetilsalicílico }\end{array}$ & $\begin{array}{l}\text { Antipirético } \\
\text { Analgésico }\end{array}$ & $\begin{array}{l}\text { Fluorescência nativa do } \\
\text { fármaco diretamente em } \\
\text { fase sólida. } \lambda_{\text {exc }}=288 \mathrm{~nm} ;\end{array}$ & $\begin{array}{l}50-170 \\
\mathrm{mg} \mathrm{g}^{-1}\end{array}$ & $2,2 \mathrm{mg} \mathrm{g}^{-1}$ & $\begin{array}{l}\text { Amostras magistrais } \\
\text { (comprimido), não } \\
\text { informados }\end{array}$
\end{tabular}

Ácido Antipirético $\lambda_{\mathrm{em}}=318 \mathrm{~nm}$.

acetilsalicílico Analgésico

Ácido

Antipirético

Fluorescência nativa do

fármaco diretamente em fase sólida. $\lambda_{\text {exc }}=288 \mathrm{~nm}$; $\lambda_{\text {em }}=318 \mathrm{~nm}$. Empregando calibração multivariada.

acetilsalicílico Analgésico

Fluorescência nativa do

fármaco impregnado em papel de filtro quantitativo.

$\lambda_{\text {exc }}=298 \mathrm{~nm} ; \lambda_{\text {em }}=411 \mathrm{~nm}$.

Ácido 2-fenil- Filtro solar

benzimidazol-

5-sulfônico

Amilorida Diurético

Carbamazepina Anticonvulsivo Fluorescência em estado sóli-

Fluorescência nativa do

fármaco retido em SAX (cloreto de trimetilaminopropil), empregando sistema de fluxo seqüencial. $\lambda_{\text {exc }}=301 \mathrm{~nm}$; $\lambda_{\mathrm{em}}=681 \mathrm{~nm}$.

Fluorescência nativa do fármaco retido em Sephadex SP-C25, empregando sistema por injeção em fluxo. $\lambda_{\text {exc }}=291 \mathrm{~nm} ; \lambda_{\mathrm{em}}=419 \mathrm{~nm}$ do do fármaco suportado em membranas de nylon, empregando calibração multivariada.

$\begin{array}{lll}\begin{array}{l}\text { Cloroquina } \\ \text { (fosfato) }\end{array} & \text { Antimalárico } & \text { Fluorescência nativa do } \\ & \text { Antireumático } & \text { fármaco diretamente em fase } \\ & \text { sólida. } \lambda_{\text {exc }}=290 \mathrm{~nm} ; \\ & \lambda_{\text {em }}=413 \mathrm{~nm} .\end{array}$

Naproxeno Antiinflamató- Fármaco extraído em memrio, analgésico, brana de fase reversa, antipirético

medindo a fluorescência nativa do naproxeno diretamente na superfície sólida. $\lambda_{\text {exc }}=272 \mathrm{~nm} ; \lambda_{\text {em }}=350 \mathrm{~nm}$.

Paracetamol Antipirético Analgésico

Fluorescência nativa do

fármaco diretamente em fase sólida. $\lambda_{\text {exc }}=333 \mathrm{~nm}$; $\lambda_{\mathrm{em}}=382 \mathrm{~nm}$.

Triamtereno Diurético
Fluorescência nativa do fármaco retido em Sephadex SP-C25, empregando sistema por injeção em fluxo. $\lambda_{\text {exc }}=240 \mathrm{~nm} ; \lambda_{\mathrm{em}}=440 \mathrm{~nm}$.
$50-170$ Não informado Amostras preparadas em

$\mathrm{mg} \mathrm{g}^{-1}$ laboratório (comprimido)

$\begin{array}{lll}10-400 & 4 \mu \mathrm{mol} \mathrm{L}{ }^{-1} & \\ \mu \mathrm{mol} \mathrm{L}^{-1} & & \text { Aspirina }^{\circledR} \text { (comprimido), } \\ & \begin{array}{l}\text { Bayer; } \mathrm{AAS}^{\circledR} \text { (comprimido), } \\ \text { não informado } \\ \end{array} \\ & \text { Análise de soro } \\ 0,001-2,5 & 12 \mathrm{ng} \mathrm{mL}^{-1} \quad \begin{array}{l}\text { Não analisa amostras } \\ \text { farmacêuticas }\end{array}\end{array}$

$\begin{array}{lll}10-600 & 0,92 \mu \mathrm{g} \mathrm{L}^{-1} & \text { Ameride }^{\circledR} \text { (comprimido), } \\ \mu \mathrm{g} \mathrm{L}{ }^{-1} & & \text { Dupont } \\ & \text { PharmaKalten }{ }^{\circledR} \text { (comprimido), } \\ & \text { Zeneca Farma }\end{array}$

Não informado Não informado

Carbamzepina (comprimido), 114 Denver Farma;

Tegretol ${ }^{\circledR}$ (comprimido), Novartis;Tegretol $^{\circledR}$ (suspensão oral), Novartis

$300-700 \quad 90 \mathrm{mg} \mathrm{g}^{-1} \quad$ Amostras magistrais

$\mathrm{mg} \mathrm{g}^{-1}$ (cápsulas)

$0,014-0,250 \quad 5 \mathrm{ng} \mathrm{mL}^{-1}$

Aplicado em análise de soro

$\mu \mathrm{g} \mathrm{mL}$

$100-400 \quad 13 \mathrm{mg} \mathrm{g}^{-1}$

Amostras preparadas em

$\mathrm{mg} \mathrm{g}^{-1}$

aboratório (comprimido)

$10-400 \quad 0,95 \mathrm{ng} \mathrm{mL}^{-1}$

Triniagar $^{\circledR}$ (comprimido), ng $\mathrm{mL}^{-1}$

não informado

Salidur $^{\circledR}$ (comprimido), não informado permitindo a determinação de alguns fármacos em matrizes onde se encontram a níveis de traços, como em alimentos. ${ }^{5}$

Complexos formados entre fármacos e compostos orgânicos como 4-cloro-7-nitrobenzo-2-oxa-1,3-diazol e 4-cloro-7-nitrobenzofurazan para determinar gentamicina ${ }^{109}$ e nortriptilina, ${ }^{110}$ respectivamente, permitiram a quantificação destes fármacos a níveis de $\mu \mathrm{g} \mathrm{mL}^{-1}$.

\section{Fluorescência nativa de íons metálicos}

A quantificação da intensidade fluorescente emitida por compostos que possuem fluorescência nativa e que, por sua vez, reagem estequiometricamente com o fármaco de interesse tem sido amplamente utilizada na determinação de princípios ativos. ${ }^{64,75-77,81,123}$

O íon cérico é um reagente oxidante bastante versátil que reage estequiometricamente com vários fármacos. Sua forma reduzida apresenta fluorescência a $357 \mathrm{~nm}$ em meio ácido, tendo sido empregado na análise em batelada e em fluxo de princípios ativos como os antibióticos amoxilina ${ }^{123}$ e aztreonam $;{ }^{75}$ dipirona $;{ }^{76}$ isoniazida (tuberculostático), ${ }^{77}$ cloreto de isoxsuprina ${ }^{64}$ (vasodi-latador) e cloreto de ritodrina (simpatomimético). ${ }^{81}$ 
Tabela 3. Determinação de fármacos baseada na formação de complexos

\begin{tabular}{|c|c|c|c|c|c|c|}
\hline $\begin{array}{l}\text { Princípio } \\
\text { ativo }\end{array}$ & Classificação & $\begin{array}{l}\text { Metodologia empregada } \\
\text { para gerar luminescência }\end{array}$ & $\begin{array}{l}\text { Faixa de } \\
\text { análise }\end{array}$ & $\begin{array}{l}\text { Limite de } \\
\text { detecção }\end{array}$ & $\begin{array}{l}\text { Marca (forma farmacêutica) } \\
\text { e Fabricante }\end{array}$ & Ref. \\
\hline Ácido nalidíxico & $\begin{array}{l}\text { Antibiótico } \\
\text { Quimioterá- } \\
\text { pico }\end{array}$ & $\begin{array}{l}\text { Fluorescência do complexo } \\
\text { entre o fármaco a } \\
\gamma \text {-ciclodextrina em pH } 2,8 . \\
\lambda_{\text {exc }}=314 \mathrm{~nm} ; \lambda_{\text {em }}=357 \mathrm{~nm} .\end{array}$ & $\begin{array}{l}0,1-2,0 \\
\mu \mathrm{g} \mathrm{mL}-1\end{array}$ & $14 \mathrm{ng} \mathrm{mL}^{-1}$ & Análise de urina & 102 \\
\hline Dapsona & $\begin{array}{l}\text { Antileprótico } \\
\text { antimalárico }\end{array}$ & $\begin{array}{l}\text { Fluorescência do complexo } \\
\text { entre o fármaco e a } \beta \text {-ciclo- } \\
\text { dextrina na presença de } \\
\text { álcoois lineares (1-butanol } \\
\text { ou 1-pentanol) a } 1 \%(\mathrm{v} / \mathrm{v}) \text {. }\end{array}$ & $\begin{array}{l}3,4-1,5 \times 10^{3} \\
\mathrm{ng} \mathrm{mL}^{-1}\end{array}$ & $1,02 \mathrm{ng} \mathrm{mL}^{-1}$ & $\begin{array}{l}\text { Balance }^{\circledR} \text { (comprimido), } \\
\text { Pharmaceutical Factory } \\
\text { Shangai } \\
\text { Sunve }^{\circledR} \text { (comprimido), Shangai } \\
\text { Pharmaceutical Co. Ltd. }^{\text {Parmace }}\end{array}$ & 94 \\
\hline $\begin{array}{l}\text { Diclofenaco } \\
\text { de sódio }\end{array}$ & $\begin{array}{l}\text { Antiinflama- } \\
\text { tório }\end{array}$ & $\begin{array}{l}\text { Fluorescência do complexo } \\
(1: 1) \text { formado pelo fármaco } \\
\text { e a } \alpha \text {-ciclodextrina em } \\
\text { solução aquosa. }\end{array}$ & $\begin{array}{l}0-5 \\
\mu \mathrm{g} \mathrm{mL}-1\end{array}$ & $0,07 \mu \mathrm{g} \mathrm{mL}^{-1}$ & $\begin{array}{l}\text { Damixa }^{\circledR} \text { (comprimido), } \\
\text { Merck Dioxaflex }^{\circledR} \\
\text { (comprimido), } \\
\text { Bagó Vesalion }^{\circledR} \\
\text { (comprimido), } \\
\text { Argentia Voltarén } \\
{ }^{\circledR} \\
\text { (comprimido), Novartis }\end{array}$ & 95 \\
\hline Fluoxetina & Antidepressivo & $\begin{array}{l}\text { Fluorescência do complexo } \\
\text { (1:1) formado pelo fármaco } \\
\text { (fluoxetina) e a metil- } \\
\beta \text {-ciclodextrina. } \\
\lambda_{\text {exc }}=224 \mathrm{~nm} ; \lambda_{\text {em }}=294 \mathrm{~nm} .\end{array}$ & $\begin{array}{l}40-1000 \\
\mu g \mathrm{~L}^{-1}\end{array}$ & $10 \mu \mathrm{g} \mathrm{L}^{-1}$ & $\begin{array}{l}\text { Prozac }^{\circledR} \text { (comprimido), } \\
\text { não informado } \\
\text { Adofen }^{\circledR} \text { (comprimido), } \\
\text { não informado } \\
\text { Reneuronl }^{\circledR} \text { (comprimido), } \\
\text { não informado }\end{array}$ & 117 \\
\hline Ibuprofeno & $\begin{array}{l}\text { Antiinflama- } \\
\text { tório } \\
\text { Antipirético } \\
\text { Analgésico }\end{array}$ & $\begin{array}{l}\text { Fluorescência do complexo } \\
(1: 1) \text { entre o fármaco e a } \\
\beta \text {-ciclodextrina em hidróxido } \\
\text { de sódio }(10>\mathrm{pH}>7) \text {. }\end{array}$ & $\begin{array}{l}0,1-2,0 \\
\mu \mathrm{g} \mathrm{mL}-1\end{array}$ & $0,03 \mu \mathrm{g} \mathrm{mL}^{-1}$ & $\begin{array}{l}\text { Ibuprofeno (comprimido), } \\
\text { Aria } \\
\text { Ibuprofeno (comprimido), } \\
\text { Rouzdarou }\end{array}$ & 96 \\
\hline Ibuprofeno & $\begin{array}{l}\text { Antiinflama- } \\
\text { tório } \\
\text { Antipirético } \\
\text { Analgésico }\end{array}$ & $\begin{array}{l}\text { Fluorescência do complexo } \\
(1: 1) \text { fármaco }-\beta \text {-ciclodex- } \\
\text { trina em } \mathrm{NH}_{3} 0,02 \mathrm{~mol} \mathrm{~L}^{-1} \text {, } \\
\text { a } 10^{\circ} \mathrm{C} \text {. }\end{array}$ & $\begin{array}{l}4,7-58 \\
\mu g \mathrm{~mL}^{-1}\end{array}$ & $1,6 \mu \mathrm{g} \mathrm{mL}^{-1}$ & $\begin{array}{l}\text { Druisel Ibuprofeno } \\
\text { (comprimido), Northia }^{\circledR} \\
\text { IBU-Buscapina }^{\circledR} \\
\text { (comprimido), Boehringer } \\
\text { Ingelheim } \\
\text { Ibupirac Fem }^{\circledR} \\
\text { (comprimido), Monsanto } \\
\text { Ibupirac Migra } \\
\text { (comprimido), Monsanto }^{\circledR} \\
\text { Ibupirac Flex } \\
\text { (comprimido), Monsanto }\end{array}$ & 97 \\
\hline Menadiona & $\begin{array}{l}\text { Vitamina } \mathrm{K}_{3} \\
\text { Antitumoral }\end{array}$ & $\begin{array}{l}\text { Fluorescência do complexo } \\
(1: 1) \text { menadiona - } \\
\beta \text {-ciclodextrina em tampão } \\
\text { citrato (pH 6,2). }\end{array}$ & $\begin{array}{l}0,1-2,0 \\
\mathrm{mg} \mathrm{L}^{-1}\end{array}$ & $0,022 \mathrm{mg} \mathrm{L}^{-1}$ & $\begin{array}{l}\text { Vitaencil CKP } \\
\text { (comprimido), } \\
\text { Wassermann Lab. } \\
\text { BIO-HUBBER } \\
\text { (comprimido), ICN } \\
\text { Ibérica S.A. }\end{array}$ & 98 \\
\hline Piroxicam & $\begin{array}{l}\text { Antiinflama- } \\
\text { tório }\end{array}$ & $\begin{array}{l}\text { Fluorescência do complexo } \\
(1: 2) \text { formado pelo fármaco } \\
\text { (fluoxetina) e a } \beta \text {-ciclodex- } \\
\text { trina em pH ácido }(3,5) \text {. } \\
\lambda_{\text {exc }}=320 \mathrm{~nm} ; \lambda_{\text {em }}=450 \mathrm{~nm} \text {. }\end{array}$ & $\begin{array}{l}0,02-1 \\
\mu \mathrm{g} \mathrm{mL}-1\end{array}$ & $0,02 \mu \mathrm{g} \mathrm{mL}^{-1}$ & $\begin{array}{l}\text { Solocalm }{ }^{\circledR} \text { (cápsulas), } \\
\text { Microsules-Bernabo }\end{array}$ & 99 \\
\hline $\begin{array}{l}\text { Ácido } \\
\text { Flufenâmico } \\
\text { (derivado do } \\
\text { ácido antranílico) }\end{array}$ & $\begin{array}{l}\text { Antiinflama- } \\
\text { tório }\end{array}$ & $\begin{array}{l}\text { Fluorescência do complexo } \\
\text { ternário formado pelo fárma- } \\
\text { co, térbio (III) e óxido de trio- } \\
\text { ctilfosfina em solução aquosa } \\
\text { de Triton X-100. }\end{array}$ & $\begin{array}{l}4 \times 10^{-10}-10^{-5} \\
\mathrm{~mol} \mathrm{~L}{ }^{-1}\end{array}$ & $2 \times 10^{-10} \mathrm{~mol} \mathrm{~L}^{-1}$ & Análise de soro & 100 \\
\hline $\begin{array}{l}\text { Ácido } \\
\text { Mefenâmico } \\
\text { (derivado do } \\
\text { ácido antranílico) }\end{array}$ & $\begin{array}{l}\text { Antiinflama- } \\
\text { tório }\end{array}$ & $\begin{array}{l}\text { Fluorescência do complexo } \\
\text { ternário formado pelo fárma- } \\
\text { co, térbio (III) e óxido de } \\
\text { trioctilfosfina em solução } \\
\text { aquosa de Triton X-100. }\end{array}$ & $\begin{array}{l}4 \times 10^{-9}-10^{-5} \\
\mathrm{~mol} \mathrm{~L}^{-1}\end{array}$ & $2 \times 10^{-9} \mathrm{~mol} \mathrm{~L}^{-1}$ & Análise de soro & 100 \\
\hline
\end{tabular}


Tabela 3. continuação

\begin{tabular}{|c|c|c|c|c|c|c|}
\hline $\begin{array}{l}\text { Princípio } \\
\text { ativo }\end{array}$ & Classificação & $\begin{array}{l}\text { Metodologia empregada } \\
\text { para gerar luminescência }\end{array}$ & $\begin{array}{l}\text { Faixa de } \\
\text { análise }\end{array}$ & $\begin{array}{l}\text { Limite de } \\
\text { detecção }\end{array}$ & $\begin{array}{l}\text { Marca (forma farmacêutica) } \\
\text { e Fabricante }\end{array}$ & Ref. \\
\hline $\begin{array}{l}\text { Ácido } \\
\text { nalidíxico }\end{array}$ & $\begin{array}{l}\text { Antibiótico } \\
\text { Quimiote- } \\
\text { rápico }\end{array}$ & $\begin{array}{l}\text { Fluorescência do complexo } \\
\text { formado pelo fármaco e o íon } \\
\text { térbio (III) em tampão TRIS } \\
\text { em pH 8,0. }\end{array}$ & $\begin{array}{l}0,02-7,0 \\
\mu g \mathrm{~mL}^{-1}\end{array}$ & $6,0 \times 10^{-3} \mu \mathrm{g} \mathrm{mL}^{-1}$ & Análise de soro & 101 \\
\hline $\begin{array}{l}\text { Ácido } \\
p \text {-amino- } \\
\text { benzóico }\end{array}$ & $\begin{array}{l}\text { Avalia indireta- } \\
\text { mente a função } \\
\text { pancreática } \\
\text { Componente de } \\
\text { filtros solares }\end{array}$ & $\begin{array}{l}\text { Fluorescência baseada na } \\
\text { formação do complexo } \\
\text { ternário formado pelo } \\
\text { fármaco, térbio (III) e } \\
\text { EDTA em meio básico } \\
\text { de } \mathrm{NaOH}(\mathrm{pH} 12,6) \text {. }\end{array}$ & $\begin{array}{l}0,01-10 \\
\mu \mathrm{mol} \mathrm{L}-1\end{array}$ & $0,01 \mu \mathrm{mol} \mathrm{L}-1$ & Análise de urina e soro & 103 \\
\hline $\begin{array}{l}\text { Ácido } \\
\text { Tolfenâmico } \\
\text { (derivado do } \\
\text { ácido antranílico) }\end{array}$ & $\begin{array}{l}\text { Antiinflama- } \\
\text { tório }\end{array}$ & $\begin{array}{l}\text { Fluorescência do complexo } \\
\text { ternário formado pelo } \\
\text { fármaco, térbio (III) e } \\
\text { óxido de trioctilfosfina em } \\
\text { solução aquosa de } \\
\text { Triton X-100. }\end{array}$ & $\begin{array}{l}10^{-9}-10^{-5} \\
\mathrm{~mol} \mathrm{~L}^{-1}\end{array}$ & $5 \times 10^{-10} \mathrm{~mol} \mathrm{~L}^{-1}$ & Análise de soro & 100 \\
\hline $\begin{array}{l}\text { Furosemida } \\
\text { (derivado do } \\
\text { ácido antranílico) }\end{array}$ & Diurético & $\begin{array}{l}\text { Fluorescência do complexo } \\
\text { ternário formado pelo } \\
\text { fármaco, térbio (III) e óxido } \\
\text { de trioctilfosfina em solução } \\
\text { aquosa de Triton X-100. }\end{array}$ & $\begin{array}{l}10^{-9}-10^{-5} \\
\mathrm{~mol} \mathrm{~L}^{-1}\end{array}$ & $5 \times 10^{-10} \mathrm{~mol} \mathrm{~L}^{-1}$ & Análise de soro & 100 \\
\hline Norfloxacina & Antibiótico & $\begin{array}{l}\text { Fluorescência do complexo } \\
\text { formado pelo fármaco e o íon } \\
\text { térbio (III) em tampão } \\
\text { TRIS em pH 8,0. }\end{array}$ & $\begin{array}{l}0,4-9,0 \\
\mu g \mathrm{~mL}^{-1}\end{array}$ & $0,13 \mu \mathrm{g} \mathrm{mL}^{-1}$ & Análise de soro & 101 \\
\hline $\begin{array}{l}\text { Ácido } \\
\text { nalidíxico }\end{array}$ & $\begin{array}{l}\text { Antibiótico } \\
\text { Quimiote- } \\
\text { rápico }\end{array}$ & $\begin{array}{l}\text { Fluorescência dos quelatos } \\
\text { do fármaco-metal. Os quela- } \\
\text { tos foram obtidos com os } \\
\text { seguintes metais: zircônió } \\
\text { molibdênio }^{\text {b; vanádio }}{ }^{\mathrm{c}} \text { e } \\
\text { tungstênio }^{\mathrm{d}}\end{array}$ & $\begin{array}{l}\mathrm{a}, \mathrm{b}, \mathrm{c}, \mathrm{d}, 10-60 \\
\mathrm{ng} \mathrm{mL}\end{array}$ & $\begin{array}{l}{ }^{\mathrm{a}} 1,8 \mathrm{ng} \mathrm{mL}^{-1} \\
{ }^{\mathrm{b}} 1,7 \mathrm{ng} \mathrm{mL}^{-1} \\
{ }^{\mathrm{c}} 1,3 \mathrm{ng} \mathrm{mL}^{-1} \\
{ }^{\mathrm{d}} 1,8 \mathrm{ng} \mathrm{mL}^{-1}\end{array}$ & $\begin{array}{l}\text { Nalidixic }^{\circledR} \text { (comprimido), } \\
\text { Elnasr Pharm. Chem. Co }\end{array}$ & 104 \\
\hline $\begin{array}{l}\text { Ciproflo- } \\
\text { xacina }\end{array}$ & Antibiótico & $\begin{array}{l}\text { Fluorescência dos quelatos } \\
\text { do fármaco-metal. Os quela- } \\
\text { tos foram obtidos com os } \\
\text { seguintes metais: zircônio } \\
\text { molibdênio }^{\text {b; }} \text {; vanádioc e } \\
\text { tungstênio }^{\text {d }}\end{array}$ & $\begin{array}{l}\mathrm{a}, \mathrm{b}, \mathrm{b}, \mathrm{d}, 10-60 \\
\mathrm{ng} \mathrm{mL}\end{array}$ & $\begin{array}{l}{ }^{\mathrm{a}} 1,5 \mathrm{ng} \mathrm{mL}^{-1} \\
{ }^{\mathrm{b}} 1,4 \mathrm{ng} \mathrm{mL}^{-1} \\
{ }^{\mathrm{c}} 1,5 \mathrm{ng} \mathrm{mL}^{-1} \\
{ }^{\mathrm{d}} 1,8 \mathrm{ng} \mathrm{mL}^{-1}\end{array}$ & $\begin{array}{l}\text { Serviflox }{ }^{\circledR} \text { (comprimido), } \\
\text { Novartis Pharma } \\
\text { Cipro otic }^{\circledR} \text { (gotas), Chemical } \\
\text { Industries Development } \\
\text { Ciprofloxacin }{ }^{\circledR} \text { (injeção), } \\
\text { Amriya Pharmaceuticals }\end{array}$ & 104 \\
\hline Norfloxacina & Antibiótico & $\begin{array}{l}\text { Fluorescência dos quelatos } \\
\text { do fármaco-metal. Os quela- } \\
\text { tos foram obtidos com os } \\
\text { seguintes metais: zircônio }^{\text {a }} \\
\text { molibdênio }^{\text {b; vanádio }} \text { ve }^{\mathrm{c}} \\
\text { tungstênio }^{\mathrm{d}}\end{array}$ & $\begin{array}{l}\text { a,b,c,d } 10-60 \\
\text { ng mL }\end{array}$ & $\begin{array}{l}{ }^{\mathrm{a}} 1,3 \mathrm{ng} \mathrm{mL}^{-1} \\
{ }^{\mathrm{b}} 1,5 \mathrm{ng} \mathrm{mL}^{-1} \\
{ }^{\mathrm{c}} 1,6 \mathrm{ng} \mathrm{mL}^{-1} \\
{ }^{\mathrm{d}} 1,7 \mathrm{ng} \mathrm{mL}^{-1}\end{array}$ & $\begin{array}{l}\text { Spectrama }^{\circledR} \text { (comprimido), } \\
\text { Amoun Pharm. Ind. Co. } \\
\text { Norbactin }^{\circledR} \text { (comprimido), } \\
\text { RanbaxyOpto Q3 eye }^{\circledR} \text { (gotas), } \\
\text { Chemical Industries } \\
\text { Development }\end{array}$ & 104 \\
\hline Ofloxacina & Antibiótico & $\begin{array}{l}\text { Fluorescência dos quelatos } \\
\text { do fármaco-metal. Os quela- } \\
\text { tos foram obtidos com os } \\
\text { seguintes metais: zircônio } \\
\text { molibdênio }^{\text {b; }} \text {, vanádio }{ }^{c} \text { e } \\
\text { tungstênio }^{\text {d. }}\end{array}$ & $\begin{array}{l}\text { a,b,c,d } 10-60 \\
\text { ng mL }\end{array}$ & $\begin{array}{l}{ }^{\mathrm{a}} 1,2 \mathrm{ng} \mathrm{mL}^{-1} \\
{ }^{\mathrm{b}} 1,5 \mathrm{ng} \mathrm{mL}^{-1} \\
{ }^{\mathrm{c}} 1,8 \mathrm{ng} \mathrm{mL}^{-1} \\
{ }^{\mathrm{d}} 1,5 \mathrm{ng} \mathrm{mL}^{-1}\end{array}$ & $\begin{array}{l}\text { Tarivid }^{\circledR} \text { (comprimido), } \\
\text { Hoechst } \\
\text { Ofloxacin }{ }^{\circledR} \text { (comprimido), } \\
\text { Sedico Pharm. Co. }\end{array}$ & 104 \\
\hline Pefloxacina & Antibiótico & $\begin{array}{l}\text { Fluorescência dos quela- } \\
\text { tos do fármaco-metal. Os } \\
\text { quelatos foram obtidos com } \\
\text { os seguintes metais: zircônio } \\
\text { molibdênio }^{\text {b; }} \text {; vanádio }{ }^{c} \text { e } \\
\text { tungstênio }^{\text {d. }}\end{array}$ & $\begin{array}{l}\mathrm{a}, \mathrm{b}, \mathrm{c}, \mathrm{d} \\
\mathrm{ng} \mathrm{mL}\end{array}$ & $\begin{array}{l}{ }^{\mathrm{a}} 1,5 \mathrm{ng} \mathrm{mL}^{-1} \\
{ }^{\mathrm{b}} 1,8 \mathrm{ng} \mathrm{mL}^{-1} \\
{ }^{\mathrm{c}} 1,7 \mathrm{ng} \mathrm{mL}^{-1} \\
{ }^{\mathrm{d}} 1,6 \mathrm{ng} \mathrm{mL}^{-1}\end{array}$ & $\begin{array}{l}\text { Peflacine }{ }^{\circledR} \text { (ampola), } \\
\text { Rhone-Poulenc Rorer }\end{array}$ & 104 \\
\hline Amicasina & Antibiótico & $\begin{array}{l}\text { Fluorescência do íon } \mathrm{Eu}^{3+} \\
\text { aumentada na presença } \\
\text { do fármaco em pH 5,5. }\end{array}$ & $\begin{array}{l}10-70 \\
\mu \mathrm{g} \mathrm{mL}-1\end{array}$ & $2,2 \mu \mathrm{g} \mathrm{mL}^{-1}$ & $\begin{array}{l}\text { Amikin }^{\circledR} \text { (ampola), } \\
\text { Briston Co. }\end{array}$ & 78 \\
\hline
\end{tabular}


Tabela 3. continuação

\begin{tabular}{|c|c|c|c|c|c|c|}
\hline $\begin{array}{l}\text { Princípio } \\
\text { ativo }\end{array}$ & Classificação & $\begin{array}{l}\text { Metodologia empregada } \\
\text { para gerar luminescência }\end{array}$ & $\begin{array}{l}\text { Faixa de } \\
\text { análise }\end{array}$ & $\begin{array}{l}\text { Limite de } \\
\text { detecção }\end{array}$ & $\begin{array}{l}\text { Marca (forma farmacêutica) } \\
\text { e Fabricante }\end{array}$ & Ref. \\
\hline $\begin{array}{l}\text { Clorotetra- } \\
\text { ciclina }\end{array}$ & Antibiótico & $\begin{array}{l}\text { Fluorescência íon } \mathrm{Eu}^{3+} \\
\text { aumentada na presença } \\
\text { do fármaco. }\end{array}$ & Não informada & $2 \mathrm{ng} \mathrm{mL}^{-1}$ & Não reportada & 132 \\
\hline Diclofenaco & $\begin{array}{l}\text { Antiinflama- } \\
\text { tório }\end{array}$ & $\begin{array}{l}\text { Fluorescência íon } \mathrm{Eu}^{3+} \\
\text { aumentada na presença } \\
\text { do fármaco. }\end{array}$ & $\begin{array}{l}10-200 \\
\mu \mathrm{g} \mathrm{mL} L^{-1}\end{array}$ & Não reportado & $\begin{array}{l}\text { Voltaren }^{\circledR} \text { (comprimido), } \\
\text { Ciba Giegy } \\
\text { Rheumafen }{ }^{\circledR} \text { (cápsula), } \\
\text { Apic Co. } \\
\text { Voltaren }{ }^{\circledR} \text { (ampola), } \\
\text { Ciba Giegy } \\
\text { Voltaren }^{\circledR} \text { (suspensão), } \\
\text { Ciba Giegy } \\
\text { Voltaren }^{\circledR} \text { (ungüiento), } \\
\text { Ciba Giegy }\end{array}$ & 105 \\
\hline Doxiciclina & Antibiótico & $\begin{array}{l}\text { Fluorescência íon } \mathrm{Eu}^{3+} \\
\text { aumentada na presença } \\
\text { do fármaco. }\end{array}$ & Não informada & $3 \mathrm{ng} \mathrm{mL}^{-1}$ & Não reportada & 132 \\
\hline Gentamicina & Antibiótico & $\begin{array}{l}\text { Fluorescência do íon } \mathrm{Eu}^{3+} \\
\text { aumentada na presença } \\
\text { do fármaco em pH 5,5. }\end{array}$ & $\begin{array}{l}10-70 \\
\mu g \mathrm{~mL}^{-1}\end{array}$ & $2,6 \mu \mathrm{g} \mathrm{mL}-1$ & $\begin{array}{l}\text { Gentamicina (ungüento), } \\
\text { Memphis Co. } \\
\text { Gentamicina (ampola), } \\
\text { Memphis Co. }\end{array}$ & 78 \\
\hline Kanamicina & Antibiótico & $\begin{array}{l}\text { Fluorescência do íon } \mathrm{Eu}^{3+} \\
\text { aumentada na presença } \\
\text { do fármaco em pH 5,5. }\end{array}$ & $\begin{array}{l}10-70 \\
\mu \mathrm{g} \mathrm{mL}-1\end{array}$ & $2,2 \mu \mathrm{g} \mathrm{mL}-1$ & $\begin{array}{l}\text { Kanamicina (solução), } \\
\text { não informado }\end{array}$ & 78 \\
\hline Neomicina & Antibiótico & $\begin{array}{l}\text { Fluorescência do íon } \mathrm{Eu}^{3+} \\
\text { aumentada na presença } \\
\text { do fármaco em pH } 5,5 \text {. }\end{array}$ & $\begin{array}{l}20-100 \\
\mu g \mathrm{~mL}^{-1}\end{array}$ & $2,3 \mu \mathrm{g} \mathrm{mL}-1$ & $\begin{array}{l}\text { Neomicina (comprimido), } \\
\text { Memphis Co. }\end{array}$ & 78 \\
\hline Piroxicam & $\begin{array}{l}\text { Antiinflama- } \\
\text { tório }\end{array}$ & $\begin{array}{l}\text { Fluorescência do íon } \mathrm{Eu}^{3+} \\
\text { aumentada na presença } \\
\text { do fármaco em metanol e } \\
\text { pH 9,0 (tampão TRIS). }\end{array}$ & $\begin{array}{l}0,1-2,00 \\
\mathrm{mg} \mathrm{mL}^{-1}\end{array}$ & $23,0 \mu \mathrm{g} \mathrm{mL}$ & $\begin{array}{l}\text { Não relatada (comprimido), } \\
\text { não informado } \\
\text { Não relatada (cápsula), } \\
\text { não informado }\end{array}$ & 106 \\
\hline Tetraciclina & Antibiótico & $\begin{array}{l}\text { Fluorescência do íon } \mathrm{Eu}^{3+} \\
\text { aumentada na presença } \\
\text { do fármaco. }\end{array}$ & Não informada & $1 \mathrm{ng} \mathrm{mL}^{-1}$ & Não relatada & 132 \\
\hline Tobramicina & Antibiótico & $\begin{array}{l}\text { Fluorescência do íon } \mathrm{Eu}^{3+} \\
\text { aumentada na presença } \\
\text { do fármaco em } \mathrm{pH} 5,5 \text {. }\end{array}$ & $\begin{array}{l}10-70 \\
\mu g \mathrm{~mL}^{-1}\end{array}$ & $2,6 \mu \mathrm{g} \mathrm{mL}-1$ & $\begin{array}{l}\text { Nebcin }^{\circledR} \text { (ampola), } \\
\text { Lily França S.A. }\end{array}$ & 78 \\
\hline Cloroxina & Antimicótico & $\begin{array}{l}\text { Fluorescência do complexo } \\
\text { fármaco - alumínio (III), em } \\
\text { meio micelar de lauril sulfato } \\
\text { de sódio, em estado estacio- } \\
\text { nário e em sistema por } \\
\text { injeção em fluxo }{ }^{\mathrm{b}} \text {. }\end{array}$ & $\begin{array}{l}{ }^{\mathrm{a}} 0,02-51 \\
\mu \mathrm{g} \mathrm{mL} \mathrm{mL}^{-1} \\
\mathrm{~b} 0,56-56 \\
\mu \mathrm{g} \mathrm{mL} \mathrm{mL}^{-1}\end{array}$ & $\begin{array}{l}{ }^{\mathrm{a}} 5,0 \mathrm{nmol} \mathrm{L} \\
{ }^{-1} \\
{ }^{0} 0,13 \mu \mathrm{g} \mathrm{mL}^{-1}\end{array}$ & $\begin{array}{l}\text { Não informado (comprimido), } \\
\text { não informado } \\
\text { Não informado (pílula), } \\
\text { não informado }\end{array}$ & 107 \\
\hline Norfloxacina & Antibiótico & $\begin{array}{l}\text { Fluorescência do complexo } \\
\text { fármaco - alumínio (III) em } \\
\text { meio micelar de dodecil } \\
\text { sulfato de sódio em pH } 4.0\end{array}$ & $\begin{array}{l}0,003-6,8 \\
\mu \mathrm{g} \mathrm{mL}-1\end{array}$ & $0,4 \mathrm{ng} \mathrm{mL}^{-1}$ & $\begin{array}{l}\text { Senro }^{\circledR} \text { (cápsula), Biosart } \\
\text { Espeden }^{\circledR} \text { (comprimido), Vita } \\
\text { Vicnasl }^{\circledR} \text { (comprimido), Semar } \\
\text { Baccial }^{\circledR} \text { (comprimido), } \\
\text { Pharmaceuticals S.A. } \\
\text { Noroxin }^{\circledR} \text { (comprimido), Merk } \\
\text { Sharp and Dohme S.A. } \\
\text { Uroctal Norfloxacina }^{\circledR} \\
\text { (comprimido), Funkk S.A. } \text { Amicrobin }^{\circledR} \text { (cápsula), } \\
\text { Hosbon, S.A. }_{\text {Chibroxin }}{ }^{\circledR} \text { (solução), } \\
\text { Merk Sharp and Dohme-Chibret }\end{array}$ & 108 \\
\hline Tenoxicam & $\begin{array}{l}\text { Antiinflama- } \\
\text { tório } \\
\text { Analgésico }\end{array}$ & $\begin{array}{l}\text { Fluorescência do complexo } \\
\text { (1:1) fármaco-alumínio (III) } \\
\text { em ácido nítrico } 0,5 \mathrm{~mol} \mathrm{~L}^{-1} \text {. }\end{array}$ & $\begin{array}{l}16-100 \\
\text { ng mL-1 }\end{array}$ & $4,7 \mathrm{ng} \mathrm{mL}^{-1}$ & $\begin{array}{l}\text { Epicotil }^{\circledR} \text { (comprimido), } \\
\text { não informado } \\
\text { Epicotil }^{\circledR} \text { (supositório), } \\
\text { não informado } \\
\text { Epicotil }^{\circledR} \text { (pó liofilizado), } \\
\text { não informado }\end{array}$ & 74 \\
\hline
\end{tabular}


Tabela 3. continuação

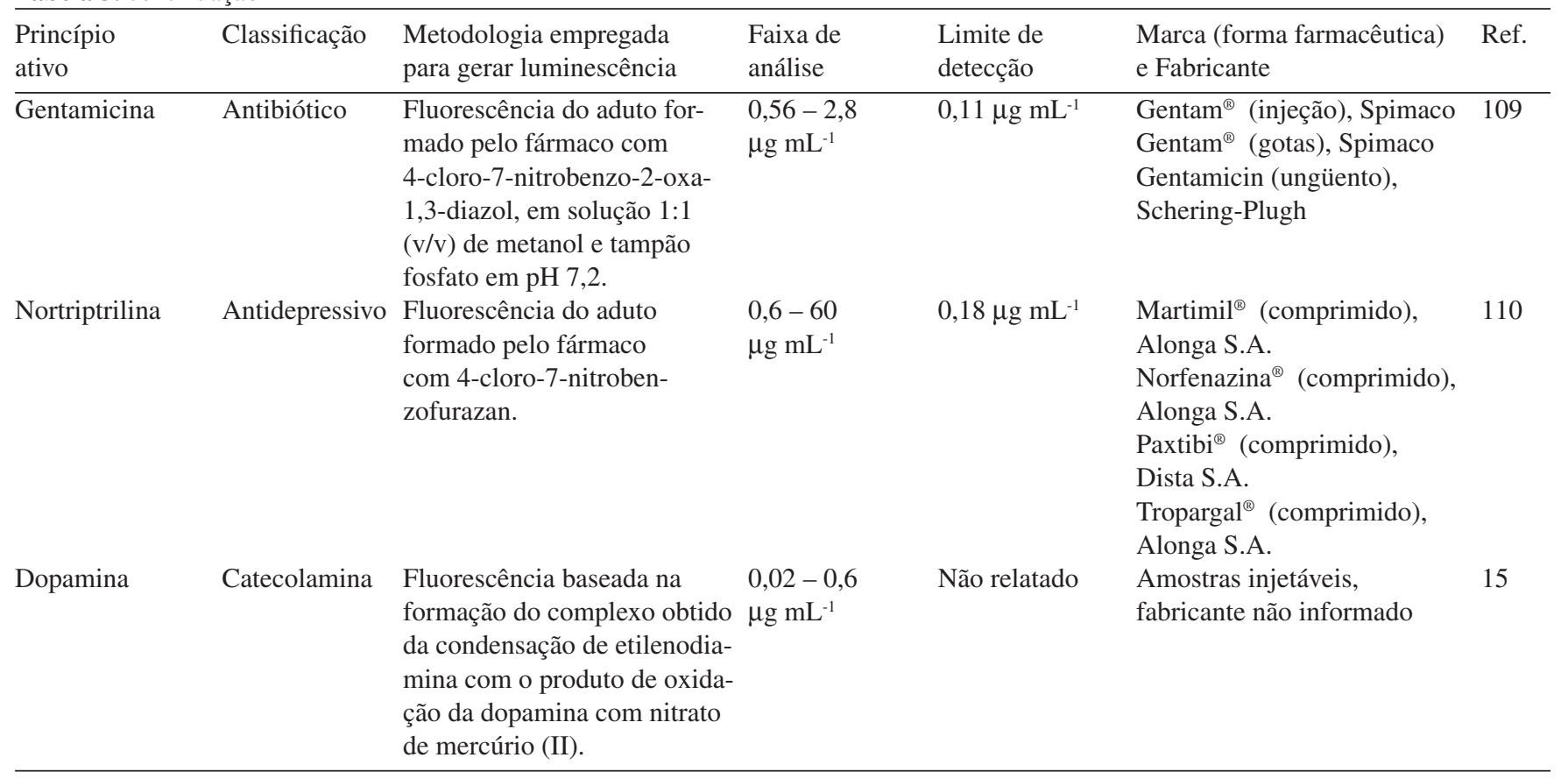

$\mathrm{O}$ íon fluorescente $\mathrm{TlCl}_{3}{ }^{2-}$ formado pela redução quantitativa do íon $\mathrm{Tl}^{3+}$ na presença do fármaco em meio de ácido clorídrico tem sido explorado na quantificação em fluxo de fármacos contendo grupos tióis como a tiopronina ( $N$-2-mercaptopropioniglicina) e a penicilamina (3-mercapto-D-valina), ${ }^{79}$ empregados no tratamento de doenças do fígado e pele, e na artrite reumatóide, respectivamente.

\section{Fluoróforos obtidos por derivatização do fármaco}

Processos mais complexos, com a finalidade de converter o fármaco em um derivado fluorescente,,$^{15,82-84}$ permitindo aumentar ou gerar fluorescência a partir de compostos não fluorescentes, têm sido propostos.

Desta forma, o ácido ascórbico (vitamina C) tem sido quantificado em batelada e em fluxo em diferentes formulações comerciais, através da fluorescência da quinoxalina obtida pela reação de $o$-fenilenodiamina com o ácido deidroascórbico (produto da oxidação aeróbia do fármaco). ${ }^{12} \mathrm{O}$ antiipertensivo captropil, foi quantificado a partir da fluorescência do ácido 1,2-diidroxinaftaleno-4-sulfônico, produto da redução estequiométrica do ácido 1,2-naftoquinona-4-sulfônico na presença do fármaco. ${ }^{13} \mathrm{~A}$ dopamina foi determinada através da fluorescência do produto de condensação da etilenodiamina com a DOPAquinona, produto de oxidação da dopamina com nitrato de mercúrio (II), permitindo analisar dopamina na faixa de concentração em níveis biológicos $\left(\mathrm{ng} \mathrm{mL}^{-1}\right){ }^{15}$

Aly ${ }^{82}$ desenvolveu uma metodologia para a determinação de cloreto de prenalterol, agente simpatomimético, baseada na derivatização deste fármaco em duas etapas, na primeira, é realizada a derivatização para obter um nitro-derivado, e na segunda o fármaco nitrogenado reage com 2-cianoacetamida em meio amoniacal, obtendo-se um composto fluorescente.

O anestésico procaína foi determinado pelo composto fluorescente obtido da reação do fármaco com a fluorescamina em tampão citrato/fosfato em $\mathrm{pH} 4,0,{ }^{83}$ permitindo a determinação deste anestésico na faixa de concentração de $n g \mathrm{~mL}^{-1}$. Finalmente, a tiamina (vitamina $B_{1}$ ) foi quantificada através da fluorescência emitida pelo composto 1-alquil-tio-2-alquil-isoindol, obtido da derivatização do grupo amino primário da vitamina com o $o$-ftalaldeído na presença de 2-mercaptoetanol.

\section{Quantificação de fármacos baseada em diversos tipos de reações}

\section{Determinação de fármacos baseada em reações fotoquímicas}

A combinação de reações fotoquímicas com detecção fluorimétrica em sistemas hidrodinâmicos tem demonstrado ser uma estratégia versátil, simples, seletiva e sensível para a determinação de diversos fármacos em medicamentos. ${ }^{88-91}$ Desta forma, o antiinflamatório diclofenaco tem sido quantificado sob diferentes apresentações comerciais (suspensão, comprimido, supositório), empregando análise por injeção seqüencial (SIA) após irradiação com radiação ultravioleta ( $279 \mathrm{~nm}$ ) durante 30 s. Após este tempo a solução de diclofenaco apresenta uma nova banda de emissão em $420 \mathrm{~nm}$, com uma intensidade 485 vezes maior quando comparada com a banda de fluorescência do diclofenaco em sua forma nativa em $310 \mathrm{~nm} .^{88}$

A vitamina $\mathrm{K}_{3}$ (menadiona) foi determinada através da quantificação de sua forma reduzida (diidronaftoquinona), fotoquimicamente obtida pela irradiação UV de uma solução do fármaco preparada em meio micelar de docecilsulfato de sódio (no qual é solúvel) e empregando análise por injeção em fluxo. ${ }^{89}$

$\mathrm{O}$ antibiótico sulfametazina foi determinado em diferentes preparações comerciais (comprimido, pó, suspensão), através da fluorescência induzida fotoquimicamente a $287 \mathrm{~nm}$, na presença de sulfito de sódio e tampão borato ( $\mathrm{pH} 8,8)$ empregando sistema por injeção em fluxo. ${ }^{90}$ De forma similar, a fluorescência da tiamina tem sido induzida através da reação fotoquímica empregando radiação ultravioleta de $370 \mathrm{~nm}$ na presença de uma solução aquosa contendo $2 \%$ de $\mathrm{NaOH}$ e $0,4 \%$ de sulfito de sódio. ${ }^{91}$

\section{Determinação baseada na hidrólise de fármacos}

Muitos fármacos apresentam fluorescência nativa fraca, contudo a intensidade da emissão pode aumentar após hidrólise ácida, ${ }^{93}$ bási$\mathrm{ca}^{120,121}$ ou até ser promovida em meio orgânico e catalisada por íons metálicos. ${ }^{92}$ Neste sentido, Fernández e colaboradores descreveram um método para determinação de ampicilina em cápsula e suspensão, baseada na hidrólise ácida ( $\mathrm{pH} 3,7$ ) do fármaco, catalisada pelo íon cúprico em meio micelar de dodecilsulfato de sódio empregando sistema em fluxo. ${ }^{92}$ 
A fluorescência nativa do salicilato (produto da hidrólise básica) foi aproveitada por Martos e colaboradores ${ }^{121}$ na quantificação de ácido acetilsalicílico em comprimidos e empregando calibração multivariada. Linares e colaboradore ${ }^{135}$ também determinaram ácido acetilsalicílico a partir da quantificação da fluorescência em matriz sólida do salicilato em amostras de fármacos e de soro sanguíneo.

Por outro lado, os sedativos derivados das benzodiazepinas, diazepam, oxazepam e nitrazepam, foram quantificados após hidrólise em meio de ácido sulfúrico e etanol para os dois primeiros e em metanol para o último. ${ }^{93}$

O antimicótico tolnaftato foi satisfatoriamente determinado após hidrólise em meio básico para formar o fluoróforo $\beta$-naftolato, em preparações comerciais na forma de creme e pó. ${ }^{61}$

\section{Determinação baseada na cinética da reação luminescente de fármacos}

Outros tipos de configurações menos exploradas, tais como a inibição da velocidade de oxidação ${ }^{1}$ ou de redução ${ }^{111}$ de compostos fluorescentes, na presença do fármaco têm sido descritos na literatura.

Feng e colaboradores ${ }^{1}$ descreveram a determinação de ácido ascórbico ao nível de traços, baseada na inibição da velocidade de oxidação do fluoróforo pironina Y pelo nitrito na presença de ácido ascórbico. $\mathrm{O}$ método foi convenientemente empregado na determinação de ácido ascórbico em comprimidos, injeções, vegetais, frutas e bebidas.

Por outro lado, Pérez e colaboradores ${ }^{111}$ descreveram um método em fluxo para a determinação do hipotensivo nitroprussida, baseado na inibição da velocidade de fotorredução do fluoróforo fluoxina (fluorescência rosa, $\lambda_{\text {emissão }}=543 \mathrm{~nm}$ ) pelo EDTA na presença do fármaco. Quando uma solução contendo floxina e EDTA é irradiada na ausência de oxigênio com luz branca em um $\mathrm{pH}$ adequado, a fotorredução do fluoróforo ocorre e a cor rosa desaparece. Na presença de nitroprussida a velocidade da reação fotoquímica diminui grandemente e esta mudança pode ser quantificada pela intensidade de fluorescência da floxina. Esta inibição pode ser explicada pela interação entre a nitroprussida com o estado triplete da floxina, assim a redução da cor devido à reação com o EDTA é impedida. O método foi aplicado satisfatoriamente na determinação do fármaco em preparações farmacêuticas e em soro sangüíneo.

\section{Fluorescência nativa da espécie oxidada ou reduzida do princípio ativo}

A fluorescência inerente das espécies oxidadas e reduzidas de fármacos não fluorescentes tem sido aplicada na determinação de ácido fólico, ${ }^{138}$ vitamina $\mathrm{K}_{3}{ }^{86}$ e prenalterol. ${ }^{87}$ Zhang e Tang ${ }^{138}$ descrevem a determinação de ácido fólico pela oxidação on line do fármaco com chumbo em um sistema em fluxo. A metodologia foi empregada na determinação em comprimidos e em teste de dissolução de medicamentos.

A vitamina $\mathrm{K}_{3}$ foi determinada pela fluorescência inerente da espécie reduzida do fármaco, obtida pela reação com zinco metálico em meio de ácido clorídrico, empregado na forma de um reator de fase sólida em um sistema em fluxo. A metodologia foi empregada na determinação de vitamina $\mathrm{K}_{3}$ em diferentes formulações comerciais (comprimidos, solução e injetáveis) com sucesso.

Finalmente, o agente simpatomimético prenalterol foi determinado a partir da quantificação da forma oxidada fluorescente do fármaco pela ação de hexacianoferrato de potássio em tampão borato a $\mathrm{pH}$ 9,2 , sendo aplicada na determinação do fármaco em comprimidos e injetáveis. ${ }^{87}$

\section{Determinação de fármacos por métodos indiretos}

A determinação indireta de fármacos tem sido aplicada para quantificação de antiinflamatórios, antibióticos e vitaminas. ${ }^{14,16,17,85}$ Suárez e Díaz ${ }^{14}$ desenvolveram um método para determinar cloramfenicol através de um ensaio competitivo fluorescente realizado em fluxo e baseado na competição pelos sítios de reconhecimento em um polímero sintético com impressão molecular (MIP), ao qual estão ligadas moléculas de estrutura análoga ao fármaco marcadas com reagente fluorescente. De modo similar, Rachkov e colaboradores ${ }^{139}$ descreveram um método para determinação de $\beta$-estradiol, baseado em um ensaio imuno-fluorescente acoplado à cromatografia líquida e MIPs.

Os fármacos piroxicam e propanolol foram quantificados indiretamente, através da medida da intensidade emitida pelo fluoróforo formado da reação entre a $N$-bromosuccinimida e cloreto de metildilazina. ${ }^{17} \mathrm{O}$ método envolve a oxidação inicial dos fármacos com um excesso conhecido de $\mathrm{N}$-bromosuccinimida, seguida da geração do fluoróforo pela reação da $N$-bromosuccinimida não consumida com cloreto de metildilazina.

A determinação indireta das vitaminas $\mathrm{K}_{1}$ e $\mathrm{K}_{3}$ também tem sido relatada na literatura. ${ }^{16,85}$ Pérez e colaboradores ${ }^{85}$ desenvolveram um método para determinar vitamina $\mathrm{K}_{1}$ em fluxo, através da medida da fluorescência do ácido hidroxibenzóico (fluoróforo), quantitativamente gerado pela oxidação do ácido benzóico com peróxido de hidrogênio e catalisada pelo íon ferroso. O peróxido de hidrogênio foi estequiometricamente gerado, pela oxidação fotoquímica com radiação UV, da glicose na presença da vitamina.

\section{Determinação de fármacos baseada na supressão de fluorescência}

Metodologias baseadas na supressão da fluorescência têm sido empregadas para determinação de diversos analitos de interesse em inúmeras áreas de pesquisa. A teoria da supressão fluorescente tem sido descrita na literatura ${ }^{140-149}$ e basicamente é governada pela Equação de Stern-Volmer (Equação 1):

$\frac{I_{0}}{I}=1+K_{s v}[Q]$

onde, $I_{0}$ e $I$ são, respectivamente, a intensidade de fluorescência na ausência e na presença do fármaco supressor de fluorescência, $[Q]$ a concentração do fármaco e $\mathrm{K}_{\mathrm{sv}}$ é a constante de Stern-Volmer. Esta equação permitirá a quantificação do fármaco de interesse.

Baseado neste princípio, alguns grupos de pesquisa têm proposto metodologias de análise para antibióticos (derivados das cefaloporinas, metronidazol e tetraciclina $)^{21,22,126,128}$ e anti-micóticos. ${ }^{127}$

Por exemplo, Bebawy e colaboradores ${ }^{126}$ descreveram um método altamente sensível para quantificar cefoperazona de sódio, cefazolina de sódio, cefixima e ceftriaxona de sódio, todos antibióticos da família das cefalosporinas. O método baseia-se na supressão da fluorescência do íon térbio (III) em tampão TRIS quando o complexo ternário entre o $\mathrm{Tb}^{3+}$-TRIS-Fármaco é formado. Um $\mathrm{pH}$ de 10 permitiu a quantificação da cefoperazona de sódio, e um $\mathrm{pH}$ de 8 permitiu a determinação dos outros fármacos. A metodologia foi satisfatoriamente aplicada em formulações comerciais com diferentes apresentações, como soluções e cápsulas.

A determinação de formaldeído, que possui propriedades terapêuticas como anti-séptico e antimicótico, foi proposta através da supressão da fluorescência do bromato de acridina amarela pelo íon brometo, catalisada pelo fármaco (formaldeído) em meio ácido, empregando sistema por injeção em fluxo. A metodologia foi satisfatoriamente aplicada na determinação de preparação comercial (Viberol ${ }^{\circledR}$ ) contendo $45 \mathrm{mg} \mathrm{mL}^{-1}$ de fármaco, assim como na análise 
de alimentos e ambiental. ${ }^{127}$

Os antibióticos metronidazol e tetraciclina também foram quantificados através da supressão da fluorescência. Sulkowska ${ }^{128}$ relatou a determinação de metronidazol a partir da supressão da fluorescência dos resíduos de triptofanil contidos na proteína de soro albumina na presença do fármaco. A metodologia foi aplicada na determinação de metronidazol em comprimidos. A determinação da tetraciclina foi realizada através de um sensor construído empregando como fase sensora uma membrana plastificada imobilizada na ponta de um feixe bifurcado de fibras ópticas. A membrana foi preparada imobilizando o fluoróforo 1,4-bi(5,5'-dimetilbenzoxazol-1',3'-il-2') benzeno em uma matriz polimérica de PVC e bis(2-etilexil)sebacato (DOS). Na presença do fármaco a intensidade de fluorescência diminui e esta pode ser relacionada com a concentração de tetraciclina presente na amostra. A metodologia foi aplicada na determinação do fármaco em comprimidos. ${ }^{22}$

\section{Determinação de fármacos através de reações quimiluminescentes}

A análise empregando quimiluminescência oferece alta sensibilidade, ampla faixa de resposta linear e instrumentação simples. A vitamina $\mathrm{K}_{3}$ tem sido quantificada pela medida da quimi-luminescência gerada pela reação entre luminol e peróxido de hidrogênio, catalisada por hematina. ${ }^{16}$ Neste caso, o peróxido de hidrogênio é estequiometricamente gerado pela oxidação fotoquímica, com radiação UV, de etanol na presença da vitamina.

Quando acoplada a sistemas em fluxo, a quimiluminescência fornece uma metodologia de baixo custo, rápida, simples e altamente reprodutível para a quantificação, com sucesso, de fármacos como cefmetazol, ${ }^{46}$ gentamicina, ${ }^{49}$ dipirona, ${ }^{3,55,56}$ cloranfenicol,${ }^{52}$ antibióticos derivados da fluoroquinolona ${ }^{45}$ e filtros solares. ${ }^{57}$

Fukutsu e colaboradore ${ }^{46}$ determinaram cefmetazol, um derivado semi-sintético do antibiótico cefamicina, em um sistema por injeção em fluxo. Neste sistema a quimiluminescência entre o antibiótico e o luminol foi induzida pela oxidação do luminol com a espécie superóxido, gerada da decomposição do grupo $\beta$-lactâmico do antibiótico em meio alcalino. ${ }^{150}$ Esta metodologia permitiu a determinação de traços deste fármaco em águas de limpeza de equipamentos industriais, como reatores, centrífugas, filtros, pulverizadores e tanques da indústria farmacêutica Sankyo Co. Ltd. ${ }^{46}$

O antibiótico gentamicina tem sido quantificado empregando análise em fluxo e a quimiluminescência do complexo peróxi-oxalato. ${ }^{49}$ Neste caso, o fármaco foi previamente derivatizado com $o$-ftalaldeido, com a finalidade de obter o ativador necessário para a reação. $\mathrm{O}$ catalisador usado foi o imidazol e a reação quimiluminescente foi realizada empregando dodecilsulfato de sódio (meio micelar) como carregador para evitar a degradação do peróxi-oxalato. A metodologia permitiu a determinação de gentamicina em várias formulações oftálmicas comerciais, permitindo análises na faixa de concentrações entre 4 e $30 \mu \mathrm{g} \mathrm{mL}^{-1}$.

A determinação da dipirona foi realizada pela geração da luminescência após a oxidação do grupo sulfito da analgina $\left(\mathrm{SO}_{3}{ }^{2-}\right)$ pelo $\mathrm{MnO}_{2}$ em meio ácido para formar dióxido de enxofre excitado $\left(\mathrm{SO}_{2}{ }^{2}\right)$. Para aumentar a intensidade luminescente foi adicionada Rodamina B (fluoróforo) que gera uma luminescência mais intensa, após sua reação com o $\mathrm{SO}_{2}{ }^{*}$, uma vez que a energia adicional do sulfito pode ser facilmente transferida a um fluoróforo intencionalmente adicionado ao sistema. Esta metodologia foi aplicada na determinação do fármaco em comprimidos como Dipirona ${ }^{\circledR}$, Novalgina ${ }^{\circledR}$ e Metamizol ${ }^{\circledR}$ e em testes de dissolução. ${ }^{55}$ Huang e colaboradores ${ }^{56}$ determinaram dipirona pela auto-oxidação do grupo sulfito em meio de ácido sulfúrico contendo $0,1 \%$ de Tween 80 (meio micelar) e empregando
Rodamina 6G para aumentar a sensibilidade do método.

A determinação do cloranfenicol, um nitro composto, foi realizada pela geração química da luminescência da reação entre os produtos da fotólise em solução aquosa do cloranfenicol, luminol e cobalto(II). A fotólise foi realizada empregando lâmpada de mercúrio de baixa pressão como fonte de irradiação. Neste processo os produtos da fotólise (4-nitrobenzaldeido em maior proporção) oxidam o luminol, sendo catalisado pelo íon $\mathrm{Co}^{2+}$. A metodologia foi empregada para a determinação do fármaco em diversas marcas comerciais de colírios, assim como em outros fármacos nitro-derivados como nitrofurantoina, metronidazol e nitroprussida. ${ }^{52}$

Fármacos derivados da fluoroquinolona (FQ) foram quantificados pela luminescência gerada na reação entre a fluoroquinolona complexada com íons lantanídeos e a molécula de $\mathrm{SO}_{2}{ }^{*}$, que é o produto da reação entre sulfito e íon cérico. Foram avaliadas as respostas para levofloxacina, moxifloxacina e trovafloxacina. Os íons lantanídeos empregados para complexar cada fármaco foram $\mathrm{Eu}^{3+}$ para os dois primeiros e $\mathrm{Tb}^{3+}$ para a trovafloxacina. O Esquema 5 mostra o mecanismo de determinação de trovafloxacina..$^{45}$

$$
\begin{aligned}
\mathrm{Ce}^{4+}+\mathrm{HSO}_{3}^{-} & \longrightarrow \mathrm{Ce}^{3+}+\left\{\mathrm{HSO}_{3}\right\}^{*} \\
2\left\{\mathrm{HSO}_{3}\right\}^{*} & \longrightarrow \mathrm{S}_{2} \mathrm{O}_{6}{ }^{2-}+2 \mathrm{H}^{+} \\
\mathrm{S}_{2} \mathrm{O}_{6}^{2-} & \longrightarrow \mathrm{SO}_{4}{ }^{2-}+\left\{\mathrm{SO}_{2}\right\}^{*} \\
\left\{\mathrm{SO}_{2}\right\}^{*}+\mathrm{Tb}\left(\mathrm{FQ}_{2}^{3+}\right. & \longrightarrow \mathrm{SO}_{2}+\mathrm{Tb}\left(\mathrm{FQ}^{*}\right)_{2}^{3+} \\
\mathrm{Tb}\left(\mathrm{FQ}{ }^{*}\right)_{2}^{3+} & \longrightarrow{ }^{*} \mathrm{~Tb}(\mathrm{FQ})_{2}^{3+} \\
{ }^{*} \mathrm{~Tb}(\mathrm{FQ})_{2}^{3+} & \longrightarrow \mathrm{Tb}(\mathrm{FQ})_{2}^{3+}+\mathrm{hv}
\end{aligned}
$$

Esquema 5. Mecanismo global da formação de luminescência química na determinação de trovafloxacina. $\mathrm{Tb}(\mathrm{FQ})_{2}{ }^{3+}$ : complexo Térbio (III) $e$ fluoroquinolona $(F Q)$

É conhecido que nos últimos anos tem crescido enormemente o consumo e a produção de filtros solares, como consequiência dos efeitos adversos que a irradiação UV pode causar à pele. Neste sentido, Townshend e colaboradores ${ }^{57}$ relataram a quantificação de octil-dimetil-PABA, um filtro solar de grande absortividade na região UV-B, através da quimiluminescência do fármaco induzida pelo íon $\mathrm{MnO}_{4}^{-}$em meio ácido. Esta metodologia foi eficientemente empregada na determinação do filtro solar em cremes comercialmente disponíveis, permitindo identificar o composto em concentrações na ordem de $n g \mathrm{~mL}^{-1}$.

\section{TENDÊNCIAS E PERSPECTIVAS FUTURAS}

\section{Emprego de técnicas fluorimétricas não convencionais}

No intuito de aumentar a sensibilidade e seletividade na determinação de compostos com fluorescência nativa outras técnicas fluorimétricas têm sido descritas. Dentre elas incluem-se a espectroscopia fluorescente sincronizada convencional, ${ }^{151}$ a espectroscopia sincronizada derivada, ${ }^{108,152,153,157}$ a espectroscopia fluorescente sincronizada de ângulo variável $1^{129,154,155}$ e a espectroscopia sincronizada isopotencial. ${ }^{155,156}$

Sabe-se que a fluorescência convencional envolve a obtenção de um espectro de emissão pela varredura em uma determinada faixa de comprimentos de onda $\left(\lambda_{\mathrm{em}}\right)$ quando uma amostra é irradiada com um 
comprimento de onda de excitação $\left(\lambda_{\text {exc }}\right)$ fixo. De maneira similar, um espectro de excitação é obtido pela varredura nos diferentes comprimentos de onda de excitação enquanto se registra o sinal de emissão em um único comprimento de onda. Contudo, existe a possibilidade de variar simultaneamente $\lambda_{\text {exc }}$ e $\lambda_{\text {em }}$, e dependendo da velocidade de varredura dos dois monocromadores é possível obter os diferentes formatos da técnica fluorimétrica conhecida como espectroscopia de fluorescência sincronizada.

Assim, se a velocidade de varredura é constante para os dois monocromadores, será gerado conseqüentemente um intervalo de comprimentos de onda $(\Delta \lambda)$ constante entre $\lambda_{\text {exc }}$ e $\lambda_{\text {em }}$ e neste caso obtém-se a técnica conhecida como espectroscopia de fluorescência sincronizada convencional, a qual foi introduzida por Lloyd há mais de três décadas, ${ }^{151}$ sendo esta amplamente empregada. Nos casos em que a fluorescência de um composto é mascarada pelo espalhamento de Rayleigh, esta técnica permite uma melhora nas medidas em relação ao método convencional, desde que os $\Delta \lambda$ sejam apropriadamente selecionados, os quais podem ser rápida e convenientemente determinados a partir de gráficos tridimensionais.

Se os comprimentos de onda de excitação e emissão são variados simultaneamente, porém a diferentes velocidades, a técnica é conhecida como espectroscopia de fluorescência sincronizada de ângulo variável. ${ }^{129,155}$ Essas diferentes velocidades permitem a construção de planos em ângulos entre $+90^{\circ}$ e $-90^{\circ}$ ao eixo X de excitação em toda a extensão do espectro completo. Esta técnica é mais seletiva e foi proposta por Kubic em 1980, ${ }^{154}$ e tem sido aplicada à determinação simultânea das vitaminas $\mathrm{B}_{2}$ e $\mathrm{B}_{6}{ }^{158}$ na determinação simultânea dos diuréticos, furosemida, triamteno epiretamida, ${ }^{129}$ assim como em amostras ambientais de hidro-carbonetos aromáticos policíclicos. ${ }^{159}$

Quando o ângulo da trajetória da varredura é variado continuamente para descrever algum caminho desejado, a técnica é conhecida como espectroscopia de fluorescência sincronizada de ângulo variável não-linear. ${ }^{155}$ Esta técnica tem sido empregada na determinação seletiva de cloropromazina na presença de seu produto de degradação sulfóxido de cloropromazina e de oxitetra-ciclina na presença de aditivos colocados nas formulações farmacêuticas comerciais (vitamina $\mathrm{C}$, tiamina, riboflavina, entre outros). ${ }^{160}$

A introdução de artifícios matemáticos, como o emprego da derivada de primeira e segunda ordem em combinação com a fluorimetria sincronizada, tem sido empregada para aumentar as características espectrais minoritárias e para conseguir uma identificação mais confiável. Já a segunda derivada do espectro sincronizado pode ser útil para resolver bandas muito próximas nos casos de análise de misturas. As principais características desta técnica são a seletividade, sensibilidade, rapidez, simplicidade e baixo custo. ${ }^{152} \mathrm{~A}$ técnica tem sido empregada para determinar simultaneamente meticilina e naftilina ${ }^{153}$ e norfloxacina na presença de ácido nalidíxico, ambas aplicando-se a primeira derivada do espectro sincronizado. A norfloxacina foi determinada em urina empregando-se a segunda derivada do espectro sincronizado. ${ }^{108}$ De la Pena e colaboradores ${ }^{157}$ descreveram um método para determinação simultânea dos ácidos salicílico e salicilúrico na análise de urina, através da espectroscopia sincronizada com a primeira derivada.

Finalmente, em 1996 Pulgarin e Molina ${ }^{155}$ reportaram uma nova técnica fluorimétrica chamada de espectroscopia de fluorescência sincronizada de matriz, isopotencial, onde um programa computacional obtém uma trajetória juntando pontos com a mesma intensidade (trajetória isopotencial) do espectro tridimensional completo. Esta técnica é especialmente útil para remover o sinal de fundo proveniente da matriz permitindo a determinação seletiva de algum composto em amostras complexas e tem sido satisfatoriamente aplicada na determinação de ácido gentísico ${ }^{155}$ e ácido nalidíxico ${ }^{156}$ em urina.

\section{Emprego de técnicas de separação com detecção fluorimétrica}

As Tabelas 4 e 5 relacionam os fármacos que têm sido quantificados empregando métodos de separação como CLAE ${ }^{161-177}$ (Tabela 4) e eletroforese capilar ${ }^{50,178-181}$ (Tabela 5) na análise de amostras complexas, como plasma e urina, ou na quantificação de misturas de fármacos e em estudos relacionados com bioequiva-lência, farmacocinêtica e biodisponibilidade. Desta forma, estas técnicas apresentam grande potencialidade de uso em situações específicas onde a matriz da amostra seja muito complexa.

A espectroscopia de luminescência exibe inúmeras características vantajosas quando comparada com métodos já existentes e bem estabelecidos, pois compostos que aparentemente não apresentam fluorescência nativa poderão ser detectados através de técnicas fluorescentes não-convencionais. As técnicas não-convencionais conferem maior sensibilidade e seletividade à metodologia, uma vez que não é necessário realizar etapas prévias de separação, como ocorre nos métodos cromatográficos. Ressalta-se ainda que a implementação em análise de rotina destas técnicas não-convencionais não acarretará custo adicional de instrumentação, apenas dependerá de um treinamento e um software adequados para a execução dos experimentos e para o tratamento de dados.

\section{CONSIDERAÇÕES FINAIS E CONCLUSÕES}

O controle da qualidade de produtos farmacêuticos é um ramo da química analítica que tem um grande impacto econômico, social e principalmente na saúde pública, de forma tal que o desenvolvimento de metodologias analíticas confiáveis, rápidas e precisas para determinação de seus princípios ativos ainda é bem-vindo. Neste contexto, a espectroscopia de luminescência apresenta-se como uma técnica adequada e promissora para esses objetivos.

A literatura relata uma ampla gama de metodologias analíticas empregadas para a determinação fluorescente de fármacos, que vão desde a modificação do ambiente químico ao redor do analito para promover fluorescência em solução; derivatização ou complexação da molécula alvo com outras, para gerar uma espécie fluorescente; determinação da fluorescência em fase sólida, até o emprego de técnicas fluorimétricas mais sofisticadas, como espectroscopia sincronizada, espectroscopia sincronizada derivada e fluorescência de varredura de ângulo variável. As vantagens das análises por fluorescência incluem economia, redução no tempo de análise e na quantidade de rejeitos lançados ao meio ambiente, quando comparada com análises que empregam técnicas de separação acopladas com detecção fluorimétrica, visto que pode ser dispensado, em alguns casos, o pré-tratamento de amostra, e até o preparo de soluções nos casos da determinação fluorimétrica em fase sólida.

A versatilidade das técnicas de amostragem dos novos espectrômetros de luminescência, como o acoplamento de fibras ópticas, análise em fluxo e monitoramento em fase sólida, aliada às inúmeras possibilidades para obter compostos fluorescentes, poderá implementar novas metodologias baseadas em lumi-nescência para determinação de substâncias de relevância terapêutica. Assim, a quantificação luminescente de analitos, como filtros solares orgânicos, ácido $p$-metocinâmico, 2-etil-metil-p-metoxicinamato ${ }^{182}$ e derivados da benzofenona; ${ }^{183-191}$ substâncias estrogênicas, como os derivados do estradiol; e antiinflamatórios não-esteróides (AINEs) como a indometacina, acetamicina, ibuprofeno, e muitos outros fármacos, será plausível dependendo apenas da habilidade do pesquisador para investigar e/ou explorar novas rotas alternativas que permitam quantificar esses analitos através da espectroscopia de luminescência.

Por outro lado, a análise fluorescente diretamente na matriz da amostra pode se tornar uma realidade, visto a excelente resposta 
Tabela 4. Determinação de fármacos empregando CLAE e detecção fluorimétrica

Princípio Ativo
Alcalóides derivados da efedrina\{(-) - norefedrina,
$(+)$ - norpseudoefedrina, $(-)-$ efedrina, $(+)-$ pseudo-
efedrina, $(-)-N$-metilefedrina, $(+)-N-$ metilpseudo-
efedrina $\}$ e $( \pm)$ - sinefrina
Ácido oxolínico
Captopril
Derivados do ácido quinolónico (ácido nalidíxico,
ácido 7-hidroxi-metilnalidíxico, ácido oxolínico,
ácido piromídico, ácido pipemídico) e do ácido
Derivados das quinolonas (ciprofloxacina, danoflo-
xacina, difloxacina, enrofloxacina, flumequina,
marbofloxacina, ácido nalidixico, ácido oxolínico
e sarafloxacina)
Derivados da tetraciclina (clorotetraciclina,
doxiciclina, oxitetraciclina e tetraciclina)
Digoxina

Classificação
Estimulantes simp
perda de apetite e
Antibiótico
Antiipertensivo
Quimioterápicos
Antibióticos

Antibióticos

Antibióticos

Tratamento de falência cardíaca

Tratamento de falência cardíaca

Antibióticos

Diuréticos

Anticoncepcionais

Anticoncepcionais

Diurético

Hipoglicêmico

Antimicótico
$17 \alpha$-etinilestradiol, 4-nonilfenol, bisfenol A)

Furosemida

Gliburida

Itraconazol

$\alpha$-Metildopa

Triamtereno
Antiipertensivo

Diurético
Na planta Fontinalis antipyretica 162

Plasma, para estudos

farmacocinéticos.

Urina, para monitoramento

de 6 ácidos derivados de ácido quinolónico e cinolónico. cinolónico (cinoxacina)

Carnes de frango, porco, bovino, ovino e peixe.

Comprimidos contendo cada fármaco individualmente. Soluções de digoxina e seus metabólitos (digoxigenina, digoxigenina monodigitoxosida, digoxigenina bisdigitoxisida, diidrodigoxina. Combina imuno-ensaio com HPLC.

Soro e plasma, para estudos farmacocinéticos.

Carnes de gado e porco.

Urina de voluntários sadios.

Amostras sintéticas de água contendo níveis de estrogênios na faixa de concentração de ng $\mathrm{L}^{-1}$. Urina proveniente de voluntários de ambos os sexos.

Leite de vaca na presença de outros diuréticos, drogas e antibióticos usadas na dieta do gado

Plasma, para realizar estudos farmacocinéticos, biodisponibilidade e bioequivalência.

Plasma, para monitoramento em níveis terapêuticos em pacientes com transplante de medula óssea.

Plasma, para estudos de bioequivalência.

Urina, para monitoramento de

17 diuréticos. Apenas o triamtereno foi monitorado por fluorescência. que a determinação de medicamentos diretamente em fase sólida tem apresentado. Isto abre a possibilidade de desenvolvimento de metodologias de análise para quantificar princípios ativos em outros tipos de formulações como cremes, géis e ungüentos, além das amostras sólidas (comprimidos pulverizados e cápsulas) que já têm sido propostas na literatura.
A quimiluminescência como ferramenta analítica também pode oferecer muitas vantagens, principalmente em sistemas que possuem boa eficiência quântica, como luminol e peroxi-oxalato. Contudo, pesquisas que elucidem reação quimiluminescente de fármacos (derivatizados ou não) têm sido muito pouco exploradas, o que torna esta uma área de pesquisa bastante interessante. As 
Tabela 5. Determinação de fármacos empregando electroforese capilar e detecção fluorimétrica

\begin{tabular}{l} 
Princípio Ativo \\
\hline Digoxina e gentamicina \\
$\begin{array}{l}\text { Diuréticos (amilorida, bendroflumetiazida, } \\
\text { bumetanida e triamtereno) }\end{array}$
\end{tabular}

Furosemida

Vancomicina

Classificação

Antibiótico

Diuréticos

Diurético

Antibiótico
Amostra analisada Ref

Soluções padrão dos fármacos.

178

Medidas realizadas através de eletroforese capilar acoplada a um ensaio imuno-fluorescente. Urina, para testes de dopping, através eletroforese capilar de zona (CZE).

Urina, através eletroforese capilar de zona (CZE) e cromatografia capilar de eletrocinética miscelar (MECC).

Plasma, através de eletroforese capilar acoplada a um ensaio imuno-fluorescente. muitas inovações das técnicas de detecção quimiluminescente também podem ser uma ferramenta promissora na determinação de moléculas de importância biomédica e ambiental conforme destacado na literatura. ${ }^{192}$

Desta forma, estudos relacionados com a utilização de métodos luminescentes em geral, na determinação de compostos farmacêuticos e cosméticos, ainda apresentam um grande campo de exploração e merecem ser incentivados.

\section{MATERIAL SUPLEMENTAR}

O diagrama de Jablonski (Figura 1S), mostrando os processos físicos que podem ocorrer após uma molécula absorver um fóton com energia da faixa ultravioleta ou visível, é apresentado como material suplementar (disponível em http://quimicanova.sbq.org.br em forma de arquivo PDF, com acesso gratuito), pois pode ser encontrado em livro texto. ${ }^{43}$

\section{REFERÊNCIAS}

1. Feng, S.; Wang, J.; Chen, X., Fan, J.; Spectrochim. Acta, Part A 2005, $61,841$.

2. Paleologos, E. K.; Stalikas, C. D.; Tzouwara-Karayanni, S. M.; Karayannis, M. I.; Anal. Chim. Acta 2001, 436, 49.

3. Song, Z. H.; Zhang, N.; Talanta 2003, 60, 161.

4. Tang, Z.; Graefe, K.; March, C.; Karnes, H. T.; Microchim. Acta 2004, $144,1$.

5. Chen, G.; Schneider, M. J.; Darwish, A. M.; Lehotay, S. J.; Freeman, D. W.; Talanta 2004, 64, 252.

6. Schneider, M. J.; J. Agric. Food Chem. 2004, 54, 7809.

7. Guilbault, G. G.; Practical Fluorescence, $2^{\text {nd }}$ ed., Wiley: New York, 1990.

8 Soper, S. A.; McGown, L. B.; Warner, I. M.; Anal. Chem. (Washington, DC, U.S.) 1994, 66, 428R

9 Murata, Y.; Matsui, H.; Hirano, K. I.; Kondo, Y.; Yanaka, A.; Nakahara, A.; Tanaka, N.; Muto, H.; J. Gastroenterology 2000, 35, 510.

10 Arancibia, J. A.; Escandar, G. M.; Talanta 2003, 60, 1113

11. Turro, N. J.; Modern Molecular Photochemistry, University Science Books: California, 1991.

12. Pérez-Ruiz, T.; Martínez-Lozano, C.; Tomás, V.; Fenol, J.; Analyst (Cambridge, U. K.) 2001, 126, 1436.

13. Al-Ghannam, S. M.; El-Brashy, A. M.; Al-Farhan, B. S.; Il Fármaco 2002, 57, 625 .

14. Suárez-Rodríguez, J. L.; Díaz-García, M. E.; Biosens. Bioelectron. 2001, 16, 955
15. Wang, H. Y.; Hui, Q. S.; Xu, L. X.; Jiang, J. G.; Sun, Y.; Anal. Chim. Acta 2003, 497, 93.

16. Pérez-Ruiz, T.; Martínez-Lozano, C.; Tomás, V.; Martín, J.; Analyst (Cambridge, U. K.) 1999, 124, 197.

17. Ramesh, K. C.; Gowda, B. G.; Seetharamappa, J.; Keshavaya, J.; J. Anal. Chem. 2003, 58, 933.

18. Li, W.; Chen, J.; Anal. Chim. Acta 1996, 331, 103.

19. Moreira, A. B.; Dias, I. L. T.; Oliveira-Neto, G.; Zagatto, E. A. G.; Kubota, L. T.; Anal. Chim. Acta 2004, 523, 49

20. Moreira, A. B.; Oliveira, H. P. M.; Atvars, T. D. Z.; Dias, I. L. T.; Oliveira-Neto, G.; Zagatto, E. A. G.; Kubota, L. T.; Anal. Chim. Acta 2005, 539, 257.

21. Liu, W.; Wang, Y.; Tang, J.; Shen, G.; Yu, R.; Anal. Sci. 1998, 14, 547.

22. Wang, Y.; Liu, W. H.; Wang, K. M.; Shen, G. L.; Yu, R. Q.; Talanta $1998,47,33$

23. Warner, I. M.; McGown, L. B.; Anal. Chem. (Washington, DC, U. S.) 1992, 64, 343R

24. Warner, I. M.; McGown, L. B.; Anal. Chem. (Washington, DC, U. S.) 1988, 60, 162R.

25. Flannigan, D. J.; Hopkins, S. D.; Suslick, K. S.; J. Organomet. Chem. 2005, 690, 3513

26. Yasui, Y.; Tuziuti, T.; Sivakumar, M.; Iida, Y.; Appl. Spectrosc. 2004, 39, 399.

27. Brenner, M. P.; Hilgenfeldt, S.; Lohse, D.; Rev. Mod. Phys. 2002, 74, 425.

28. Margulis, M. A.; Margulis, I. M.; Ultrason. Sonochem. 2002, 9, 1.

29. Yuen, S.; Schreyer, M.; Finlay, W. H.; Lobengerg, R.; Moussa, W.; Appl. Phys. Lett. 2006, 88, 123901.

30. Bukvetskii, B. V.; Mirochnik, A. G.; Zhikhareva, P. A.; Karasev, V. E.; J. Struct. Chem. 2006, 47, 575.

31. Bulgakov, R. G.; Kuleshov, S. P.; Zuzlov, A. N.; Vafin, R. R.; Russ. Chem. Bull. 2004, 53, 2712.

32. Eddingsaas, N. C.; Suslick, K. S.; Nature (London, U. K.) 2006, 444, 163.

33. Jia, Y.; Yei, M.; Jia, W.; Opt. Mater. 2006, 28, 974.

34. Kher, R. S.; Panigrahi, A. K.; Dhoble, S. J.; Khokhar, M. S. K.; Radiat. Prot. Dosim. 2006, 119, 66

35. Kabakov, D. V.; Kiselev, S. V.; Seregina, E. A.; Tikhonov, G. V.; High Energy Chem. 2007, 41, 71.

36. Santana, G. C.; Mello, A. N.; Valerio, M. E. G.; Macedo, Z. S.; J. Mater. Sci. 2007, 42, 2231

37. Shimizu, N.; Mitamura, N.; Takeuchi, A.; Hashimoto, T.; Radiat. Meas. 2006, 41, 831.

38. Kurk, K.; Mathur, V. K.; McKeever, S. W.; Townsend, P. D.; Valberg, L.; Radiat. Prot. Dosim. 2006, 119, 134. 
39. Raffi, J.; Gelly, S.; Barral, L.; Burger, F.; Piccerelle, P.; Prinderre, P.; Baron, M.; Chamayou, A.; Spectrochim. Acta, Part A 2002, 58, 1313.

40. Furetta, C.; Kitis, G.; J. Mater. Sci. 2004, 39, 2277.

41. Dyke, K.; Bioluminescence and Chemiluminescence: Instruments and Applications, CRC Press, Inc.: Florida, 1985, vol. 2.

42 Lakowicz, J. R.; Principles of Fluorescense Spectroscopy, $2^{\text {nd }}$ ed., Plenum Press: New York, 1998.

43. Skoog, D. A.; West, D. M.; Holler, F. J.; Fundamentals of analytical Chemistry, $7^{\text {th }}$ ed., Saunders College Publishing: New York, 1996.

44. Waseem, A.; Yaqood, M.; Nabi, A.; Luminescence 2006, 21, 174.

45. Ocaña, J. A.; Barragán, F. J.; Callejón, M.; De La Rosa, F.; Microchim. Acta 2004, 144, 207.

46. Fukutsu, N.; Konse, T.; Kawasaki, T.; Saito, K.; Nakazawa, H.; J. Pharm. Biomed. Anal. 2006, 41, 599.

47. Gundermann, K. D.; McCapra, F. Em Chemiluminescence in Organic Chemistry; Hafner, K.; Rees, C. W.; Trost, B. M., eds.; Springer-Verlag: Berlin, 1987, vol. 23.

48. Stevani, C. V.; Baader, W. J.; Quim. Nova 1999, 22, 715.

49. Fernández-Ramos, J. M.; García-Campaña, A. M.; Ales-Barrero, F.; Bosque-Sendra, J. M.; Talanta 2006, 69, 763.

50. Zhu, R.; Kok, W. T.; J. Pharm. Biomed. Anal. 1998, 17, 985.

51. Huang, B.; Li, J.; Zhang, L.; Cheng, J. K.; Anal. Chem. (Washington, DC, U.S.) 1996, 68, 2366.

52. David, V.; Saèz, R. M. M.; Mateo, J. V. G.; Calatayud, J. M.; Analyst (Cambridge, U. K.) 2000, 125, 1313.

53. Chandross, E. A.; Tetrahedron Lett. 1963, 761.

54. Baader, W. J.; Stevani, C. V.; Bastos, E. L. Em The Chemistry of Peroxides; Rappoport Z., ed.; John Wiley: New York, 2006, vol. 2, cap. 16.

55. Zhao, L.; Li, B.; Zhang, Z.; Lin, J. M.; Sens. Actuators, B 2004, 97, 266.

56. Huang, Y. M.; Zhang, C.; Zhang, X. R.; Zhang, Z. J.; Fresenius J. Anal. Chem. 1999, 365, 381

57. Townshend, A.; Wheatley, R. A.; Chisvert, A.; Salvador, A.; Anal. Chim. Acta 2002, 462, 209.

58. Fernández, R.; Bello, M. A.; Calléjón, M.; Jiménez, J. C.; Guiraúm, A.; Talanta 2002, 56, 571

59. Salem, A. A.; Barsoum, B. N.; Izake, E. L.; Spectrochim. Acta, Part A 2004, 60, 771.

60. Solich, P.; Polydorou, C. K.; Koupparis, M. A.; Efstathiou, C. E.; Anal. Chim. Acta 2001, 438, 131.

61. Khashaba, P. Y.; El-Shabouri, S. R.; Mohamed, A. M.; J. Pharm. Biomed. Anal. 2000, 22, 363.

62. Arancibia, J. A.; Nepote, A. J.; Escandar, G. M.; Olivieri, A. C.; Anal. Chim. Acta 2000, 419, 159.

63. Sádecká, J.; Cakrt, M.; Hercegová, A.; Polonský, J.; Skacáni, I.; J. Pharm. Biomed. Anal. 2001, 25, 881.

64. Alarfaj, N. A. A.; J. Pharm. Biomed. Anal. 2002, 28, 331.

65. Fernández, R.; Bello, M. A.; Callejón, M.; Jiménez, J. C.; Guiraúm, A.; Talanta 1999, 49, 881.

66. Ocaña, J. A.; Barragán, F. J.; Callejón, M.; Analyst (Cambridge, U. K.) 2000, 125, 2322.

67. Manzoori, J. L.; Amjadi, M.; Microchim. Acta 2003, 143, 39.

68. Damiani, P. C.; Bearzotti, M.; Cabezón, M.; Olivieri, A. C.; J. Pharm. Biomed. Anal. 1998, 17, 233.

69. Barary, M. H.; Abdel-Hay, M. H.; Sabry, S. M.; Belal, T. S.; J. Pharm. Biomed. Anal. 2004, 34, 221.

70. Ibañez, G. A.; Escandar, G. M.; J. Pharm. Biomed. Anal. 2005, 37, 149.

71. Pulgarín, J. A. M.; Bermejo, L. F. G.; Talanta 2000, 51, 89.

72. Aparico, I.; Bello, M. A.; Callejón, M.; Jiménez, J. C.; Guiraúm, A.; Analyst (Cambridge, U. K.) 1998, ,123, 1575.

73. Legnerová, Z.; Sklenárová, H.; Solich, P.; Talanta 2002, 58, 1151.
74. Mohamed, H. A.; Wadood, H. M. A.; Farghaly, O. A.; J. Pharm. Biomed. Anal. 2002, 28, 819.

75. Mahgoub, H.; J. Pharm. Biomed. Anal. 2003, 31, 767.

76. Pérez-Ruiz, T.; Martínez-Lozano, C.; Tomás, V.; Carpena, J.; Microchem. J. 1993, 47, 296.

77. Lapa, R. A. S.; Lima, J. L. F. C.; Santos, J. L. M.; Anal. Chim. Acta 2000, 419, 17.

78. Rizk, M.; El-Shabrawy, Y.; Zakhari, N. A.; Toubar, S. S.; Carreira, L. A.; Talanta 1995, 42, 1849.

79. Pérez-Ruiz, T.; Martínez-Lozano, C.; Tomás, V.; Cardona, C. S.; J. Pharm. Biomed. Anal. 1996, 15, 33.

80. Sastry, C. S. P.; Mangala, D. S.; Rao, K. E.; Analyst (Cambridge, U. K.) 1986, 111, 323.

81. Razak, O. A.; J. Pharm. Biomed. Anal. 1998, 18, 359.

82. Aly, F. A.; J. Pharm. Biomed. Anal. 1999, 18, 993.

83. Carretero, A. S.; Cruces-Blanco, C.; Peinado, S. F.; El Bergmi, R.; Gutiérrez, A. F.; J. Pharm. Biomed. Anal. 1999, 21, 969.

84. Viñas, P.; López-Erroz, C.; Cerdán, F. J.; Campillo, N.; HernándezCórdoba, M.; Mikrochim. Acta 2000, 134, 83.

85. Pérez-Ruiz, T.; Martínez-Lozano, C.; Tomás, V.; Martín, J.; Talanta 1999, 50, 49.

86. Torró, I. G.; Mateo, J. V. G.; Calatayud, J. M.; Analyst (Cambridge, U. K.) $1997,122,139$.

87. Aly, F. A.; J. Pharm. Biomed. Anal. 1999, 21, 483.

88. Pimenta, A. M.; Araújo, A. N.; Montenegro, M. C. B. M.; Anal. Chim. Acta 2002, 470, 185.

89. Pérez-Ruiz, T.; Martinez-Lozano, C.; Tomás, V.; Martín, J.; Anal. Chim. Acta 2004, 514, 259.

90. He, Q.; Chen, H.; Cao, X.; Microchem. J. 1999, 61, 125.

91. Chen, H.; Zhu, J.; Cao, X.; Fang, Q.; Analyst (Cambridge, U. K.) 1998 , $123,1017$.

92. Fernández-González, A.; Badía, R.; Díaz-García, M. E.; Anal. Chim. Acta 2003, 484, 223.

93. Dolejsová, J.; Solich, P.; Polydorou, C. K.; Koupparis, M. A.; Efstathiou, C. E.; J. Pharm. Biomed. Anal. 1999, 20, 357

94. Ma, L.; Tang, B.; Chu, C.; Anal. Chim. Acta 2002, 469, 273.

95. Arancibia, J. A.; Boldrini, M. A.; Escandar, G. M.; Talanta 2000, 52, 261.

96. Manzoori, J. L.; Amjadi, M.; Spectrochim. Acta, Part A 2003, 59, 909.

97. Hergert, L. A.; Escandar, G. M.; Talanta 2003, 60, 235.

98. Nevado, J. J. B.; Pulgarin, J. A. M.; Laguna, M. A. G.; Talanta 2000, 53, 951.

99. Escandar, G. M.; Analyst (Cambridge, U. K.) 1999, 124, 587.

100. Arnaud, N.; Georges, J.; Anal. Chim. Acta 2003, 476, 149.

101. Panadero, S.; Gómez-Hens, A.; Pérez-Bendito, D.; Anal. Chim. Acta 1995, 303, 39.

102. Merás, I. D.; De La Peña, A. M.; Cáceres, M. I. R.; López, F. S.; Talanta 1998, 45, 899.

103. Lianidou, E. S.; Ioannou, P.; Clin. Chem. (Washington, DC, U. S.) 1996, 42,1659 .

104. El-Kommos, M. E.; Saleh, G. A.; El-Gizawi, S. M.; Abou-Elwafa, M. A.; Talanta 2003, 60, 1033.

105. Carreira, L. A.; Rizk, M.; El-Shabrawy, Y.; Zakhari, N. A.; Toubar, S. S.; J. Pharm. Biomed. Anal. 1995, 13, 1331.

106. Al-Kindy, S. M. Z.; Al-Wishahi, A.; Suliman, F. E. O.; Talanta 2004, 64,1343.

107. Pérez-Ruiz, T.; Martínez-Lozano, C.; Tomás, V.; Carpena, J.; J. Pharm. Biomed. Anal. 1996, 14, 1505.

108. Pérez-Ruiz, T.; Martínez-Lozano, C.; Tomás, V.; Carpena, J.; Analyst (Cambridge, U. K.) 1997, 122, 705.

109. Al-Majed, A. A.; Belal, F.; Abounassif, M. A.; Khalil, N. Y.; Microchim. Acta 2003, 141, 1.

110. De La Peña, L.; Gómez-Hens, A.; Pérez-Bendito, D.; J. Pharm. Biomed. Anal. 1995, 13, 199. 
111. Pérez-Ruiz, T.; Martínez-Lozano, C.; Tomás, V.; Val, O.; Microchem. J. $1995,52,33$.

112. Vidal, M. T.; Chisvert A.; Salvador, A.; Talanta 2003, 59, 591.

113. Domínguez-Vidal, A.; Ortega-Battales, P.; Molina-Diaz, A.; Talanta 2002, 56, 1005.

114. Escandar, G. M.; Gómes, D. G.; Mansilla, A. E.; Peña A. M.; Goicoechea, H. C.; Anal. Chim. Acta 2004, 506, 161.

115. Domíngues-Vidal, A.; Ortega-Barrales, P.; Molina-Diaz, A.; J. Pharm. Biomed. Anal. 2002, 28, 721.

116. Oliva, M. D. L. A.; Olsina, R. A.; Mais, A. N.; Talanta 2005, 66, 229.

117. Berzas, J. J.; Alañon, A.; Lázaro, J. A.; Talanta 2002, 58, 301.

118. Jiménez, R. D. B.; Abiznada, A. I. J.; Moreno, F. J.; Léon, J. J. A.; Clin. Chim. Acta 1996, 249, 21.

119. Navalón, A.; Blanc, R.; Olmo, M.; Vilchez, J. L.; Talanta 1999, 48, 469.

120. Capitán-Vallvey, L. F.; Navas, N.; Del Olmo, M.; Consonni, V.; Todeschini, R.; Talanta 2000, 52, 1069.

121. Martos, N. R.; Díaz, A. M.; Navalón, A.; Payá, I. D. O.; Vallvey, L. F. C.; J. Pharm. Biomed. Anal. 2000, 23, 837.

122. Luis, M. L.; Fraga, J. M. G.; Jiménez, A. I.; Jiménez, F.; Hernández, O.; Arias, J. J.; Talanta 2004, 62, 307.

123. Peña, A. M.; Acedo-Valenzuela, M. I.; Espinosa-Mansilla, A.; SánchesMaqueda, R.; Talanta 2002, 56, 635.

124. Damiani, P.; Nepote, A. J.; Bearsotti, M.; Olivieri, A. C.; Anal. Chem. (Washington, DC, U. S.) 2004, 76, 2798.

125. Moreira, A. B.; Dias, I. L. T.; Oliveira-Neto, G.; Zagatto, E. A. G.; Ferreira, M. M. C.; Kubota, L. T.; Talanta 2005, 67, 65.

126. Bebawy, L. I.; El-Kelani, K.; Fattah, L. A.; J. Pharm. Biomed. Anal. 2003, 32, 219.

127. Pérez-Ruiz, T.; Martínez-Lozano, C.; Tomás, V.; Fenoll, J.; Anal. Bioanal. Chem. 2003, 375, 661

128. Sulkowska, A.; J. Mol. Struct. 1999, 480-481, 581

129. Sánchez, F. G.; Gutierrez, A. F.; Blanco, C. C.; Anal. Chim. Acta 1995, 306, 313.

130. Shtykov, S. N.; Smirnova, T. D.; Bylinkin, Y. G.; Zhemerichkin, D. A.; J. Anal. Chem. 2005, 60, 24.

131. Polishchuk, A. V.; Karaseva, E. T.; Medkov, M. A.; Karasev, V. E.; Russ. J. Coord. Chem. 2004, 30, 828.

132. Hirschy, L. M.; Dose, E. V.; Winefordner, J. D.; Anal. Chim. Acta 1983, $147,311$.

133. Paredes, S. F.; Sant'Ana, P.; Moreira, A. B.; Kubota, L. T.; Sotomayor, M. D. P. T.; Lanza, M. R. V.; Dias, I. L. T.; Resumos da $29^{a}$ Reunião Anual da Sociedade Brasileira de Química, Águas de Lindóia, Brasil, 2006.

134. Dias, I. L. T.; Sotomayor, M. D. P. T.; Moreira, A. B.; Kubota, L. T.; Resumos do $13^{\circ}$ Encontro Nacional de Química Analítica - $1^{\circ}$ Congresso Ibero-Americano de Química Analítica, Niterói, Brasil, 2005.

135. Linares, E. M.; Palermo, L. P.; Moreira, A. B.; Sotomayor, M. D. P. T.; Kubota L. T.; Anal. Lett. 2007, 40, 573.

136. Oh, I.; Lee, M. Y.; Lee, Y. B.; Shin, S. C.; Park, I.; Int. J. Pharm. 1998, $175,215$.

137. Perry, L. M.; Winefordner, J. D.; Talanta 1990, 37, 965.

138. Zhang, Z. Q.; Tang, Y.; Anal. Bioanal. Chem. 2005, 381, 932.

139. Rachkov, A.; McNiven, S.; El'skaya A.; Yano, K.; Karube, I.; Anal. Chim. Acta 2000, 405, 23

140. Castro, B. D.; Gameiro, P.; Lima, J. L. F. C.; Matos, C.; Reis, S.; Colloids Surf., A 2001, 190, 205.

141. Blatt, E.; Sawyer, W. H.; Biochim. Biophys. Acta 1985, 822, 43.

142. Cabrini, G.; Verkman, A. S.; Biochim. Biophys. Acta 1986, 862, 285.

143. Chalpin, D. B.; Kleinfeld, A. M.; Biochim. Biophys. Acta 1983, 731, 465.

144. Fato, R.; Battino, M.; Esposti, M. D.; Castelli, G. P.; Lenaz, G.; Biochemistry 1986, 25, 3378.
145. Dupuo-Cèzanne, L.; Sautereau, A. M.; Tocanne, J. F.; Eur. J. Biochem $1989,181,695$.

146. Haigh, E. A.; Thulborn, K. R.; Sawyer, W. H.; Biochemistry 1979, 18, 3525 .

147. Sikaris, K. A.; Sawyer, W. H.; Biochem. Pharmacol. 1982, 31, 2625.

148. Vermeir, M.; Boens, N.; Biochim. Biophys. Acta 1992, 1104, 63.

149. Blatt, E.; Ghiggino, K. P.; Sawyer, W. H.; J. Chem. Soc., Faraday Trans. 1 1981, 77, 2551

150. Kubo, H.; Saitoh, M.; Murase, S.; Inomata, T.; Yoshimura, Y.; Nakazawa, H.; Anal. Chim. Acta 1999, 389, 89.

151. Lloyd, J. B. F.; Nature 1971, 64, 231.

152. John, P.; Soutar, I.; Anal. Chem. (Washington, DC, U. S.) 1976, 48, 520 .

153. Murillo-Pulgarín, J. A.; Alañón-Molina, A.; Talanta 1994, 41, 21.

154. Kubic, T. A.; Lasher, C. M.; Dwyer, J. J.; Forensic Sci. Soc. 1983, 28, 186.

155. Murillo-Pulgarín, J. A.; Alañón-Molina, A.; Anal. Chim. Acta 1994, 296, 87

156. Murillo-Pulgarín, J. A.; Alañón-Molina, A.; López, P. F.; Talanta 1996, 43,431 .

157. Peña, A. M.; Salinas, F.; Meras, I. D.; Anal. Chem. (Washington, DC, U. S.) 1988, 60, 2493.

158. Li, Y.; Huang, X.; Xu, J.; Chen, G.; Fenxi Huaxue 1991, 19, 538.

159. Oms, M. T.; Forteza, R.; Cerda, V.; García, F.; Ramos, A. L.; Int. J. Environ. Anal. Chem. 1990, 42, 1.

160. Clark, B. J.; Fell, A. F.; Milne, K. T.; Pattie, D. M. G.; Williams, H.; Anal. Chim. Acta 1985, 170, 35.

161. Niemann, R. A.; Gay, M. L.; J. Agric. Food Chem. 2003, 51, 5630.

162. Delépée, R.; Pouliquen, H.; J. Chromatogr., B: Anal. Technol. Biomed. Life Sci. 2002, 775, 89.

163. Arroyo, C.; López-Callul, C.; García-Capdevila, L.; Gich, I.; Barbanoj, M.; Bonal, J.; J. Chromatogr., B: Anal. Technol. Biomed. Life Sci. 1997, $688,339$.

164. Merás, I. D.; Díaz, T. G.; Cáceres, M. I. R.; López, F. S.; J. Chromatogr., A 1997, 787, 119

165. Yorke, J. C.; Froc, P.; J. Chromatogr., A 2000, 882, 63.

166. Lu, H. T.; Jiang, Y.; Li, H. B.; Chen, F.; Wong, M. H.; Chromatographia 2004, 60, 259.

167. Graefe, K. A.; Tang, Z.; Karnes, T.; J. Chromatogr., B: Anal. Technol. Biomed. Life Sci. 2000, 745, 305.

168. Belsner, K.; Buchele, B.; J. Chromatogr., B: Anal. Technol. Biomed. Life Sci. 1996, 682, 95

169. Pecorelli, I.; Galarini, R.; Bibi, R.; Floridi, A; Casciarri, E.; Floridi, A.; Anal. Chim. Acta 2003, 483, 81.

170. Carda-Broch, S.; Esteve- Romero, J. S.; García-Alvarez-Coque, M. C.; Anal. Chim. Acta 1998, 375, 143.

171. Yoon, Y.; Westerhoff, P.; Snyder, S. A.; Esparza, M.; Water Res. 2003, 37,3530 .

172. Mao, L.; Sun, C.; Zhang, H.; Li Y.; Wu, D.; Anal. Chim. Acta 2004, 522, 241.

173. Shaikh, B.; J. Agric. Food Chem. 1995, 43, 2117.

174. Khatri, J.; Qassim, S.; Abed, O.; Abraham, B.; Al-lami, A.; Masood, S.; J. Pharm. Sci. 2001, 4, 201.

175. Al-Rawithi, S.; Hussein, R.; Al-Moshen, I.; Raines, D.; Ther. Drug Monit. 2001, 23, 445

176. Róna, K.; Ary, K.; Gachályi, B.; Klebovich, I.; J. Chromatogr., A 1996, 730,125

177. Guchelaar, H. J.; Chandi, L.; Schouten, O.; Brand, W. A.; Fresenius J. Anal. Chem. 1999, 363, 700.

178. Wan, Q. H.; Le, X. C.; J. Chromatogr., B: Anal. Technol. Biomed. Life Sci. 1999, 734, 31.

179. González, E.; Becerra, A.; Laserna, J. J.; J. Chromatogr., B: Anal. Technol. Biomed. Life Sci. 1996, 687, 145. 
180. Caslavska, J.; Thormann, W.; J. Chromatogr., B: Anal. Technol. Biomed. Life Sci. 2002, 770, 207.

181. Lam, M. T.; Le, X. C.; Analyst (Cambridge, U. K.) 2002, 127, 1633.

182. Smith, G. J.; Miller, I. J.; J. Photochem. Photobiol., A 1998, 118, 93.

183. Itoh, T.; Spectrochim. Acta, Part A 1999, 55, 273.

184. Nishiguchi, H.; Zhang, J. L.; Anpo, M.; Langmuir 2001, 17, 3958.

185. Turek, A. M.; Krishnamoorthy, G.; Phipps, K.; Saltiel, J.; J. Phys. Chem. A 2002, 106, 6044.

186. Holtzclaw, K. W.; Pratt, D. W.; J. Chem. Phys. 1986, 84, 4713.

187. Sun, Y. P.; Sears, D. F.; Saltiel, J.; J. Am. Chem. Soc. 1989, 111, 706.
188. Wada, S. I.; Matsushita, Y.; Obi, K.; J. Phys. Chem. A 1997, 101, 2423.

189. Kani, R.; Nakano, Y.; Yoshida, H.; Hayase, S.; Macromolecules 1998, $31,8794$.

190. Shield, S. R.; Harris, J. M.; J. Phys. Chem. B 2000, 104, 8527.

191. Nishiguchi, H.; Zhang, J. L.; Anpo, M.; Masuhara, H.; J. Phys. Chem. B 2001, 105, 3218.

192. Fletcher, K. A.; Fakayode, S. O.; Lowry, M.; Tucker, S. A.; Neal, S. L.; Kimaru, I. W.; McCarroll, M. E.; Patonay, G.; Oldham, P. B.; Rusin, O.; Strongin, R. M.; Warner, I. M.; Anal. Chem. (Washington, DC, U. S.) 2006, 78, 4047. 


\section{APLICAÇÃO E AVANÇOS DA ESPECTROSCOPIA DE LUMINESCÊNCIA EM ANÁLISES FARMACÊUTICAS}

\section{Maria D. P. T. Sotomayor}

Departamento de Química Analítica, Instituto de Química, Universidade Estadual Paulista, 14801-970 Araraquara - SP, Brasil Iara Lúcia T. Dias* e Marcos R. V. Lanza

Curso de Farmácia, Universidade São Francisco, 12916-900 Bragança Paulista - SP, Brasil

Altair B. Moreira

Departamento de Química e Ciências Ambientais, Universidade Estadual Paulista, 15054-000 São José do Rio Preto - SP,

Brasil

\section{Lauro T. Kubota}

Departamento de Química Analítica, Instituto de Química, Universidade Estadual de Campinas, 13083-970 Campinas - SP, Brasil

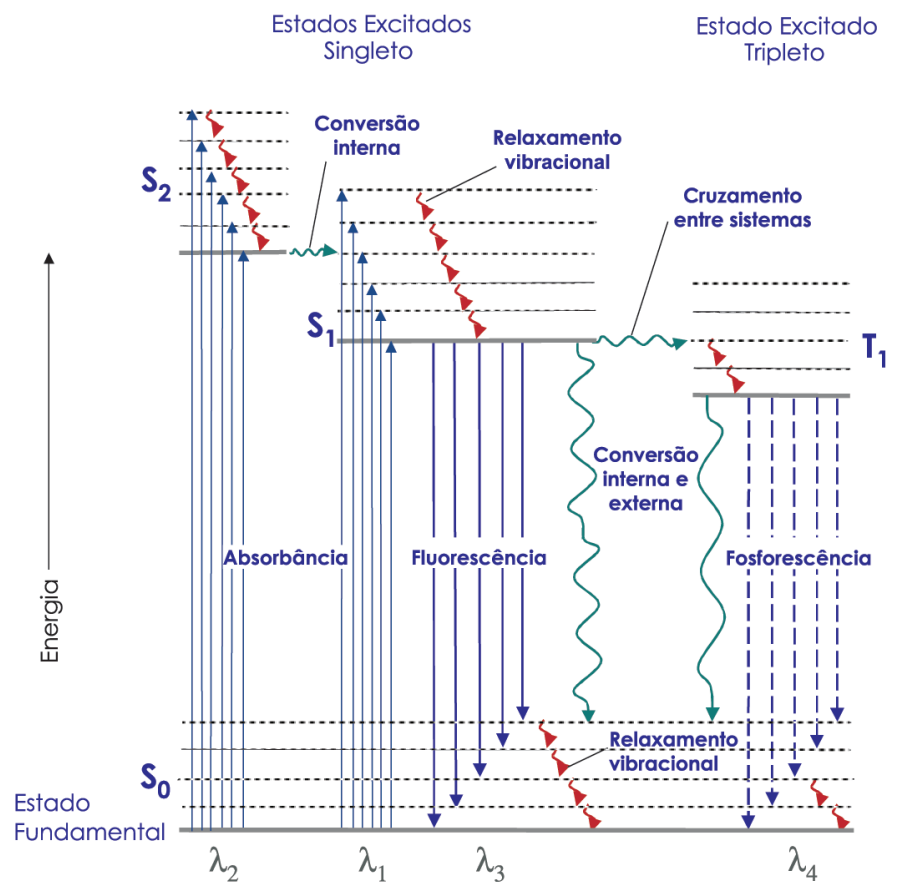

Figura 1S. Diagrama de Jablonski, mostrando os processos físicos que podem ocorrer após uma molécula absorver um fóton com energia da faixa ultravioleta ou visível. $S_{0}$ é o estado eletrônico fundamental, $S_{1}$ e e $T_{1}$ são os estados excitados singleto e tripleto de menor energia, respectivamente. $S_{2}$ é um segundo estado excitado singleto. As setas retas representam os processos envolvendo fótons, e as setas onduladas são as transições não-radioativas (que não emitem radiação $)^{43}$ 